\title{
AS PREFERÊNCIAS DOS JOVENS PARA O INGRESSO NO ENSINO SUPERIOR
}

\author{
Armando Lacerda \\ Graça Ferreira
}

\section{INTRODUÇÃO}

Desde 1967, data em que S. Ex. ${ }^{a}$ Rev. ${ }^{a}$ o Cardeal Cerejeira benze solenemente e coloca a primeira pedra da actual sede da Universidade Católica Portuguesa, que o crescimento em qualidade académica, em instalações que viabilizam os seus projectos e em novos Centros no território nacional se apresenta como um grande desafio.

A expansão da Universidade Católica no território nacional passa pela elaboração de um plano de médio a longo prazo, estando presentemente a iniciar a sua actividade em Leiria e na Figueira da Foz. Passa, igualmente, pelo desenvolvimento dos Centros já em funcionamento, com novos cursos em Lisboa, Porto, Braga e Viseu.

"A análise do sistema de ensino superior português e a comparação dos indicadores mais relevantes com os dos sistemas europeus revela que Portugal, nos últimos anos, não foi capaz de executar uma política de expansão da capacidade de acolhimento do ensino superior com vista a satisfazer a procura por parte dos jovens que terminam o ensino secundário. Verifica-se, no entanto, que os diplomados que saem do sistema, embora sejam em certas áreas excedentários em relação à oferta de emprego, continuam a não satisfazer certos domínios, e, sobretudo, certos níveis de qualificação nomeadamente técnicos médios e intermédios, para cuja oferta continuam a existir carências nítidas, que no futuro, se não forem tomadas certas medidas terão tendência a aumentar "(LOPES, 1989: 66).

O Centro Regional de Viseu da Universidade Católica Portuguesa pretende desenvolver-se de acordo com a estratégia que visa dotar o país de uma estrutura de ensino superior moderna, diversificada e ligada com a realidade.

Nas comemorações do $10 .^{\circ}$ Aniversário do Centro Regional de Viseu da Universidade Católica Portuguesa (CRV-UCP), o Magnífico Reitor da UCP, D. José Policarpo, referindo-se a este Centro Regional salientou que o mesmo estava 
ligado "a três linhas de força: o desejo de manifestar um projecto da Igreja local; a necessidade de dar resposta aos anseios e carências gerais da sociedade e da cidade de Viseu no ensino universitário e a de realizar por parte da Universidade Católica a sua vocação específica".

A realização de um estudo sobre "As preferências dos jovens para o ingresso no ensino superior" (PJIES) prendeu-se sobretudo com a intenção de colaborar directamente na concretização da segunda linha de força referida.

$O$ presente artigo pretende apresentar os instrumentos definitivos de trabalho $\mathrm{e}$ alguns resultados mais relevantes de um trabalho de pesquisa realizado no âmbito da Associação de Apoio ao Instituto Universitário de Desenvolvimento e Promoção Social (AIUDPS) ${ }^{1}$. Visto tratar-se da síntese dos resultados de um trabalho de pesquisa, podem a explicação metodológica e o texto de síntese pecar por falta de proporcionalidade relativamente à extensão do artigo.

Foi nosso intento a realização de um estudo global que, para além de outros objectivos, deveria apresentar as preferências dos jovens em termos de cursos para ingresso no ensino superior, permitindo-nos assim ter um conhecimento mais profundo da realidade e actuar, de uma forma integrada, com a estratégia de crescimento da própria Universidade.

Os objectivos gerais do trabalho realizado são os seguintes:

a) - avaliar os desejos profissionais dos jovens;

b) - analisar as preferências dos jovens em termos de cursos superiores;

c) - analisar as razões que levam os jovens a optar por determinada universidade;

d) - analisar qual o Centro da Universidade Católica Portuguesa que é preferido pelos jovens e porquê.

Para o desenvolvimento do nosso estudo partimos do universo constituído por 7790 alunos dos $9 .^{\circ}, 11 .^{\circ}$ e $12 .^{\circ}$ anos de escolaridade da Área Educativa da Região de Viseu (AERV) para a constituição de uma amostra de 873 alunos.

Optámos pelo método do inquérito e escolhemos como instrumentos de pesquisa o questionário e a escala de atitudes.

Aplicámos dois questionários diferentes, um ao $90^{\circ}$ ano de escolaridade e outro aos $11 . \% 12 .^{\circ}$ anos de escolaridade.

Iniciámos o estudo com a justificação da escolha do universo.

Prosseguimos com a apresentação do universo, cálculo da amostra e construção dos instrumentos.

Em seguida apresentámos alguns dos resultados provenientes do apuramento dos questionários e as conclusões do estudo.

Pretendemos que este estudo possa ajudar a Universidade, em particular o CRV-UCP, no seu desenvolvimento e ajudar os jovens de modo a estes poderem ver facilitada a entrada na Universidade, sem que para isso tenham que deslo118 car-se para fora da Região. 


\section{ORGANIZAÇÃO DA INVESTIGAÇÃO}

\subsection{Justificação do universo}

Ao desenvolvermos este trabalho pretendíamos também dar resposta a algumas questões que nos eram colocadas pelos responsáveis pelo crescimento e desenvolvimento do Centro Regional de Viseu da Universidade Católica Portuguesa (CRV-UCP).

A criação de novos cursos devia fornecer respostas aos desejos e necessidades sentidas pelos potenciais frequentadores.

Colocava-se desde logo uma questão fundamental: qual deveria ser o universo a considerar para o estudo a desenvolver?

Para dar resposta a tal problema procedemos a um levantamento de dados relativos à naturalidade, local de residência e escola secundária dos jovens que ingressaram no Centro Regional de Viseu da UCP desde 1985. Foi a partir dos dados obtidos que surgiu a decisão do universo de estudo.

Passamos a apresentar alguns dos valores obtidos que conduziram a tal decisão.

\section{QUADRO I}

Residência dos sujeitos que ingressaram no CRV-UCP nos diferentes cursos

\begin{tabular}{l|r|c|c|c|c|c|c|c}
\hline & \multicolumn{2}{|c|}{ HUMANIDADES } & \multicolumn{2}{c|}{ GEST ÃO D. S. } & \multicolumn{2}{c|}{ PORT.-FRANC. } & \multicolumn{2}{c}{ U.C. VISEU } \\
\cline { 2 - 9 } & $\mathrm{N}$ & $\%$ & $\mathrm{~N}$ & $\%$ & $\mathrm{~N}$ & $\%$ & $\mathrm{~N}$ & $\%$ \\
\hline \multirow{2}{*}{$\begin{array}{l}\text { AERV } \\
\text { Resto do País }\end{array}$} & 222 & 64,35 & 375 & 74,55 & 87 & 67,44 & 684 & 70,01 \\
\multicolumn{1}{c}{ TOTAL } & 123 & 35,65 & 128 & 25,45 & 42 & 32,56 & 293 & 29,99 \\
\cline { 2 - 9 } & 345 & 100,00 & 503 & 100,00 & 129 & 100,00 & 977 & 100,00 \\
\hline
\end{tabular}

Desde o ano lectivo de 1985/86 até ao ano lectivo de 1990/91 ingressaram no Centro Regional de Viseu da Universidade Católica Portuguesa nos Cursos de Humanidades, Gestão e Desenvolvimento Social e Português-Francês, 977 alunos. Destes $70,01 \%$ tinham residência nos concelhos da Área Educativa da Região de Viseu e apenas $29,99 \%$ tinham residência em concelhos do resto do país.

Verificamos também pela análise do quadro que, apesar de todos os cursos apresentarem uma percentagem superior a $60,00 \%$ de sujeitos com residência na Área Educativa da Região de Viseu, é o curso de Gestão e Desenvolvimento Social que apresenta a maior percentagem $(74,55 \%)$ de sujeitos com residência nesta área. 
QUADRO II

Residência dos sujeitos que ingressaram no CRV-UCP ao longo de 85/90

\begin{tabular}{l|r|r|r|r|r|r|r|r|r|r|r|r|r}
\hline & \multicolumn{2}{|c|}{85} & \multicolumn{2}{|c|}{86} & \multicolumn{2}{|c|}{87} & \multicolumn{2}{|c|}{88} & \multicolumn{2}{|c|}{89} & \multicolumn{2}{c}{90} \\
\cline { 2 - 12 } & $\mathrm{N}$ & $\%$ & $\mathrm{~N}$ & $\%$ & $\mathrm{~N}$ & $\%$ & $\mathrm{~N}$ & $\%$ & $\mathrm{~N}$ & $\%$ & $\mathrm{~N}$ & $\%$ \\
\hline \multirow{2}{*}{ AERV } & 102 & 66,23 & 108 & 72,97 & 107 & 70,39 & 90 & 68,70 & 127 & 71,35 & 150 & 70,09 \\
Resto do Pais & 52 & 33,77 & 40 & 27,03 & 45 & 29,61 & 41 & 31,30 & 51 & 28,65 & 64 & 29,91 \\
\cline { 2 - 12 } TOTAL & 154 & 100,00 & 148 & 100,00 & 152 & 100,00 & 131 & 100,00 & 178 & 100,00 & 214 & 100,00 \\
\hline
\end{tabular}

Desde o ano lectivo de 1985/86 até ao ano lectivo de 1990/91 a percentagem de sujeitos com residência na AERV que ingressou no CRV-UCP foi sempre superior a 66,00\%. A percentagem máxima de sujeitos com residência na AERV registou-se no ano lectivo de 1986/87 e a mínima no ano lectivo de 1985/86.

\section{QUADRO III}

Escola secundária frequentada pelos sujeitos que ingressaram no CRV-UCP nos diferentes cursos

\begin{tabular}{l|r|r|r|r|r|r|r|r}
\hline & \multicolumn{2}{|c|}{ HUMANIDADES } & \multicolumn{2}{c|}{ GEST ÃO D. S. } & \multicolumn{2}{c|}{ PORT.-FRANC. } & \multicolumn{2}{c}{ U. C. VISEU } \\
\cline { 2 - 9 } & $\mathrm{N}$ & $\%$ & $\mathrm{~N}$ & \multicolumn{1}{c|}{$\%$} & $\mathrm{~N}$ & $\%$ & $\mathrm{~N}$ & $\%$ \\
\hline \multirow{2}{*}{ AERV } & 226 & 65,51 & 380 & 75,55 & 91 & 70,54 & 697 & 71,34 \\
Resto do Pais & 119 & 34,49 & 123 & 24,45 & 38 & 29,46 & 280 & 28,66 \\
\cline { 2 - 9 } TOTAL & 345 & 100,00 & 503 & 100,00 & 129 & 100,00 & 977 & 100,00 \\
\hline
\end{tabular}

Desde o ano lectivo de 1985/86 até ao ano lectivo de 1990/91, 71,34\% dos sujeitos que ingressaram nos cursos de Humanidades, Gestão e Desenvolvimento Social e Português-Francês frequentaram escolas secundárias da Área Educativa da Região de Viseu. Os restantes $28,66 \%$ frequentaram escolas secundárias em concelhos do resto do país.

\section{QUADRO IV}

Escola secundária frequentada pelos sujeitos que ingressaram no CRV-UCP ao longo de 85/90

\begin{tabular}{l|r|r|r|r|r|r|r|r|r|r|r|r|}
\hline & \multicolumn{2}{|c|}{85} & \multicolumn{2}{|c|}{86} & \multicolumn{2}{|c|}{87} & \multicolumn{2}{|c|}{88} & \multicolumn{2}{|c|}{89} & \multicolumn{2}{|c}{90} \\
\cline { 2 - 13 } & $\mathrm{N}$ & $\%$ & $\mathrm{~N}$ & $\%$ & $\mathrm{~N}$ & $\%$ & $\mathrm{~N}$ & $\%$ & $\mathrm{~N}$ & $\%$ & $\mathrm{~N}$ & $\%$ \\
\hline \multirow{2}{*}{ AERV } & 107 & 69,48 & 103 & 69,59 & 106 & 69,74 & 88 & 67,18 & 134 & 75,28 & 159 & 74,30 \\
\multirow{4}{*}{ TOTAL } & 47 & 30,52 & 45 & 30,41 & 46 & 30,26 & 43 & 32,82 & 44 & 24,72 & 55 & 25,70 \\
\cline { 2 - 12 } & 154 & 100,00 & 148 & 100,00 & 152 & 100,00 & 131 & 100,00 & 178 & 100,00 & 214 & 100,00 \\
\hline
\end{tabular}


Desde o ano lectivo de 1985/86 até ao ano lectivo de 1990/91, a percentagem de sujeitos que ingressaram no CRV-UCP, tendo frequentado escolas secundárias da AERV, foi sempre superior a $67,00 \%$. A percentagem máxima de sujeitos nesta situação foi registada no ano lectivo de 1989/90 e a percentagem mínima no ano lectivo de 1988/89.

De acordo com os dados obtidos da análise dos quadros, não restaram dúvidas que a maioria dos sujeitos que ingressam no CRV- UCP provinham da AERV.

Assim, era de primordial importância auscultar as opiniões desses sujeitos pois eles consubstanciavam um dos pilares fundamentais do crescimento $\mathrm{e}$ desenvolvimento do CRV-UCP.

Do atrás referido não será difícil perceber a opção feita ao considerar os sujeitos que frequentam as escolas secundárias da AERV como universo para o estudo a realizar.

\subsection{Apresentação do universo e cálculo da amostra}

A Área Educativa da Região de Viseu é constituída por catorze escolas secundárias e por sete escolas $\mathrm{C}+\mathrm{S}$.

O universo é constituído por 2,941 alunos do $90^{\circ}$ ano de escolaridade, 2542 alunos do $11 .^{\circ}$ ano e 2307 alunos do $12 .^{\circ}$ ano, o que perfaz um total de 7790 alunos $^{2}$.

A partir deste universo constituímos uma amostra de 873 alunos, sendo 295 do $9 .^{\circ}$ ano de escolaridade, 290 do $11 .^{\circ}$ ano e 288 do $12 .^{\circ}$ ano. Estes resultados foram obtidos do modo seguinte:

Começámos por calcular o número de alunos (n) que iriam fazer parte da amostra. Pretendíamos que este valor fosse representativo do universo $(N)$. Para isso utilizámos a fórmula defendida por Mehok (1963:525-535), para cálculo de amostras que garantam representatividade com justificação estatística.

\section{FÓRMULA I}

Fórmula utilizada no cálculo da amostra

$$
\mathrm{N} / \mathrm{n}=\mathrm{N} *\left[\mathrm{~s}_{\mathrm{p}}^{2} / \mathrm{s}^{2}\right]+1
$$

Esta fórmula não dá directamente o valor de $n$, mas a relação $\mathrm{N} / \mathrm{n}$, pelo que, depois de conhecermos o universo, passámos à determinação da amostra. A fórmula I foi utilizada para cada ano com $s_{p}{ }^{2}=(0,03) 2$ e $s^{2}=0,25$. Desta forma o erro médio de 0,03 é ainda diminuído, uma vez que não é aplicado ao total do universo, mas a cada um dos três anos que o constituem. Depois de termos calculado o número de sujeitos de cada ano, considerámos mais $16,00 \%$ dos sujei- 
tos para eventuais falhas de conhecimento do universo ${ }^{3}$. Posteriormente os alunos foram retirados do universo por amostragem estratificada proporcionalmente por escola e escolhidos em cada escola de forma sistemática.

Pela aplicação da amostragem estratificada proporcional obtiveram-se os seguintes resultados por escola para cada ano.

\section{QUADRO V}

N..$^{\circ}$ de alunos $\left(9 .^{\circ}, 11 .^{\circ}, 12 .^{\circ}\right.$ anos $) /$ Escola N. ${ }^{\circ}$ de elementos da amostra / Ano / Escola

\begin{tabular}{|c|c|c|c|c|c|c|c|c|}
\hline \multirow{2}{*}{ AERV } & \multicolumn{2}{|c|}{$9 .^{\circ}$ ano } & \multicolumn{2}{|c|}{$11^{\circ}$ ano } & \multicolumn{2}{|c|}{$12 .^{\circ}$ ano } & \multicolumn{2}{|c|}{ TOTAL } \\
\hline & $\mathrm{N}$ & $\mathrm{n}$ & $\mathrm{N}$ & $\mathrm{n}$ & $\mathbf{N}$ & $\mathbf{n}$ & $\mathbf{N}$ & $\mathrm{n}$ \\
\hline E. S. Alves Martins & 447 & 45 & 485 & 55 & 617 & 77 & 1549 & 177 \\
\hline E. S. Carregal do Sal & 88 & 9 & 64 & 7 & 36 & 5 & 188 & 21 \\
\hline E. S. Castro Daire & 107 & 11 & 88 & 10 & 52 & 6 & 247 & 27 \\
\hline E. S. Emídio Navarro & 290 & 29 & 473 & 54 & 570 & 71 & 1333 & 154 \\
\hline E. S. Mangualde & 241 & 24 & 212 & 24 & 149 & 19 & 602 & 67 \\
\hline E. S. Mortágua & 103 & 10 & 78 & 9 & 50 & 6 & 231 & 25 \\
\hline E. S. Nelas & 92 & 9 & 90 & 10 & 63 & 8 & 245 & 27 \\
\hline E. S. Sta Comba Dão & 130 & 13 & 94 & 11 & 89 & 11 & 313 & 35 \\
\hline E. S. S. Pedro do Sul & 195 & 20 & 155 & 18 & 124 & 15 & 474 & 53 \\
\hline E. S. Sátão & 112 & 11 & 104 & 12 & 78 & 10 & 294 & 33 \\
\hline E. S. Tondela & 201 & 20 & 184 & 21 & 224 & 28 & 609 & 69 \\
\hline E. S. V. Nova de Paiva & 81 & 8 & 24 & 3 & 25 & 3 & 130 & 14 \\
\hline E. S. Viriato & 279 & 28 & 362 & 41 & 174 & 22 & 815 & 91 \\
\hline E. S. Vouzela & 62 & 6 & 25 & 3 & 47 & 6 & 134 & 15 \\
\hline E. C+S Abravezes & 86 & 9 & & & & & 86 & 9 \\
\hline $\begin{array}{l}\text { E. C+S Campo de Bes- } \\
\text { teiros }\end{array}$ & 134 & 13 & & & & & 134 & 13 \\
\hline $\begin{array}{l}\text { E. C+S Canas de } \\
\text { Senhorim }\end{array}$ & & & & & & & & \\
\hline & 69 & t & 15 & 2 & 9 & 1 & 93 & 10 \\
\hline E. C+S Figueiro & 68 & 7 & & & & & 68 & 7 \\
\hline $\begin{array}{l}\text { E. C+S Oliveira de Fra- } \\
\text { des }\end{array}$ & 91 & 9 & 63 & 7 & & & 154 & 16 \\
\hline $\begin{array}{l}\text { E. C+S Penalva do Cas- } \\
\text { telo }\end{array}$ & 65 & 7 & 26 & 3 & & & 91 & 10 \\
\hline E. $\mathrm{C}+\mathrm{S}$ Repeses & & & & & & & & \\
\hline TOTAL & 2941 & 295 & 2542 & 290 & 2307 & 288 & 7790 & 873 \\
\hline
\end{tabular}

Para procedermos à escolha sistemática, começámos por ordenar as turmas de cada ano por ordem alfabética. Em seguida os alunos foram retirados segundo um intervalo calculado para cada ano, através da relação entre o universo e a amostra ${ }^{4}$, começando sempre no número um da primeira turma de cada ano. 
Aquando da aplicação do questionário tivemos necessidade de substituir alguns dos sujeitos predeterminados pela amostragem. Esta situação verificou-se sobretudo para casos de transferências, desistências e casos de alunos que haviam respondido ao pré-questionário ou ainda para os alunos que apresentavam um número muito elevado de faltas (alunos que na opinião dos professores não voltariam às aulas). Em caso de necessidade de substituição, procurámos aplicar o questionário ao número imediatamente posterior ou imediatamente anterior.

Conseguimos por este processo aplicar os 873 questionários determinados.

\subsection{Construção dos instrumentos}

Para a realização desta pesquisa utilizámos a técnica do questionário.

Depois de conhecermos o universo, chegámos à conclusão de que era necessário construir dois instrumentos diferentes. Um, que seria para aplicar aos sujeitos do $9 .^{\circ}$ ano de escolaridade e outro para aplicar aos sujeitos dos $11 .^{\circ}$ e $12 .^{\circ}$ anos de escolaridade. A necessidade de utilização destes dois instrumentos devia-se sobretudo ao facto de estarmos a trabalhar com sujeitos de níveis etários diferentes, arrastando consigo diversos níveis de compreensão.

Assim, uma das primeiras fases da pesquisa foi dedicada à elaboração dos instrumentos de trabalho, tendo-se recorrido aos métodos especulativo e empírico.

Desta forma, para além de termos acompanhado a nossa reflexão com a leitura de alguns documentos relacionados com o estudo em causa, recorremos também à realização de algumas entrevistas.

Tratava-se de um estudo com interesse para várias instituições, nomeadamente para o Centro Regional de Viseu da Universidade Católica Portuguesa, para o Instituto de Emprego e Formação Profissional (IEFP)/ Centro de Emprego de Viseu e para a Associação de Apoio ao Instituto Universitário de Desenvolvimento e Promoção Social (AIUDPS), interessadas em promover o progresso da Região. Sentimos, por isso, a preocupação e a necessidade de ter em linha de conta os desejos e opiniões dos responsáveis destas instituições para a elaboração dos questionários.

Das reuniões que tivemos com os responsáveis pelo CRV-UCP e pela AIUDPS surgiram ideias para algumas questões relativas à opinião dos jovens em relação à Universidade e ao ingresso no ensino superior.

Tivemos também a preocupação de realizar algumas entrevistas a estudantes da AERV.

Estas entrevistas foram realizadas pela equipa posteriormente responsável pela aplicação dos questionários.

Depois de cada um dos estudantes ter respondido oralmente a algumas questões perguntámos-lhe o ano, a turma e o número, para que não viessem a ser incluídos na amostra à qual seriam aplicados os questionários. 
Efectuámos uma breve análise de conteúdo ${ }^{5}$ ao material resultante das respostas dadas pelos estudantes e obtivemos dados para a formulação dos questionários.

O pré-questionário foi aplicado a uma amostra de 62 sujeitos, sendo 10 do $9 .^{\circ}$ ano de escolaridade e 52 dos $11 . \% 12 .^{\circ}$ anos.

Depois da aplicação, não foi feita qualquer alteração ao questionário do 9..$^{\circ}$ ano de escolaridade; apenas se confirmou a necessidade da sua administração directa.

Relativamente ao pré-questionário dos $11 . \% 12 .^{\circ}$ anos de escolaridade verificou-se a necessidade de alterar algumas questões.

\subsection{Questionário definitivo}

\subsubsection{Apresentação das variáveis}

O conteúdo do questionário foi condicionado pelos objectivos da investigação.

Para avaliar as preferências dos jovens para o ingresso no ensino superior tivemos necessidade de construir dois questionários diferentes. Construímos, como já foi dito, um questionário para aplicar aos alunos do $90^{\circ}$ ano de escolaridade e outro para aplicar aos alunos dos $11 .^{\circ} / 12 .^{\circ}$ anos de escolaridade.

Os dois questionários apresentam um conjunto de variáveis comuns mas, também, algumas variáveis diferentes.

Os questionários são simples, constituídos por perguntas abertas, perguntas fechadas e perguntas de escolha múltipla. São curtos, formados por um conjunto de perguntas de fácil compreensão e resposta rápida.

Podem destacar-se em relação aos dois questionários algumas variáveis comuns. As variáveis escola, turma e número funcionam nos dois questionários como prova de fidelidade da amostra. Permitem verificar se o sujeito que respondeu ao questionário foi o pretendido, aquando da constituição da amostra, ou se houve necessidade de substituição por outro sujeito ${ }^{6}$. Estas três variáveis são ainda auxiliadas no questionário aplicado aos $11 . \% 12 .^{\circ}$ anos pela variável ano que permite fazer a distribuição de questionários iguais por dois anos diferentes.

São ainda comuns aos dois questionários as variáveis sexo, idade, estado civil, naturalidade e local de residência. Estas constituem o conjunto das variáveis indispensáveis à caracterização da amostra. Outras variáveis comuns aos dois questionários foram estudadas com o objectivo de analisar o ambiente em que vivem os sujeitos da amostra e sobretudo para permitir distribuí-los por classes sociais. São disto exemplo as variáveis, pessoas com quem vive, número de irmãos, profissão do pai, profissão da mãe, profissão das pessoas com quem vive, profissão do encarregado de educação, habilitações literárias do pai, habili- 
habilitações literárias do encarregado de educação. Para além do conjunto das variáveis já apresentadas, são ainda comuns aos dois questionários as variáveis futuro escolar, razões que levam o sujeito a deixar de estudar e o que pretende fazer quando sair da escola.

As variáveis, curso superior que gostaria de tirar, qual a razão porque o escolheu, universidade que gostaria de frequentar, qual a razão da escolha, ensino ministrado na UCP-Viseu, cursos ministrados na UCP-Viseu, são também comuns aos questionários dos $9 .^{\circ} \mathrm{e} 11 . \%^{\circ} 12 .^{\circ}$ anos.

O questionário do $9 .^{\circ}$ ano contém ainda as variáveis, disciplina preferida, área de estudos que vai escolher, razões que influenciaram a escolha da área e razão porque continua a estudar.

Do questionário aplicado aos sujeitos dos $11 . \% 12 .^{\circ}$ anos fazem parte as variáveis ensino ministrado na UCP e classe social.

\subsubsection{Aplicação dos questionários e codificação}

Na aplicação do questionário definitivo procedeu-se do seguinte modo.

Constituiu-se uma equipa de trabalho para a administração dos questionários, com o auxílio de mais duas alunas do Curso de Licenciatura em Gestão e Desenvolvimento Social.

Após ter sido autorizada, pela Directora Regional de Educação do Centro, a aplicação do questionário nas escolas secundárias e $\mathrm{C}+\mathrm{S}$ da Área Educativa da Região de Viseu, estabeleceu-se mais uma vez contacto com os respectivos Conselhos Directivos a fim de se organizar a aplicação dos mesmos.

De acordo com as listas dos sujeitos a inquirir, previamente organizadas, com número, turma e ano, foram-nos indicados os horários considerados mais adequados para o efeito.

Cada escola disponibilizou um espaço onde reunimos um grupo de alunos dos diferentes anos, colocados sempre que possível de forma intercalada para evitar qualquer tipo de influência na resposta. Antes de proceder à aplicação do questionário, fazia-se uma leitura do seu conteúdo, objectivos e finalidades, frisando sempre o carácter confidencial das respostas. Os alunos dos $11 . \%^{\circ} 12 .^{\circ}$ anos de escolaridade responderam directamente ao questionário. Os alunos do $9 .^{\circ}$ ano de escolaridade consideraram a interpretação do questionário difícil sem o auxílio do entrevistador, pelo que foi necessária a sua administração directa.

Após a aplicação dos 873 questionários procedeu-se à correcção do seu preenchimento, para posterior codificação e tratamento informático.

Utilizou-se um Sistema de Gestão de Base de Dados para criar a estrutura da base de dados que conteria a informação necessária.

A introdução da informação processou-se em duas fases.

Numa primeira fase foram introduzidos os códigos correspondentes a todas as perguntas fechadas e de escolha múltipla. Nesta fase não se utilizou qualquer folha de codificação; a informação foi transferida directamente do questionário 
para a base de dados, o que permitia a correcção de eventuais erros (através de rotinas próprias) e a percepção do questionário no seu todo.

Numa segunda fase procedeu-se à codificação de perguntas abertas. Para tal, efectuou-se a análise de conteúdo ${ }^{7}$ que se iniciou com a leitura das respostas dadas a cada pergunta nos 873 questionários aplicados. Depois de recolhidas todas as respostas formularam-se categorias às quais foram atribuídos códigos. Nesta fase foram utilizadas folhas de codificação. Posteriormente procedeu-se à introdução da informação, tendo o cuidado de a submeter a rotinas de detecção de erro.

\subsection{Organização da amostra}

Posteriormente à aplicação de todos os questionários aos sujeitos previamente determinados, à sua codificação e posterior introdução na base de dados, organizou-se a amostra para o apuramento dos resultados.

Fizemos a distribuição dos sujeitos por classe social e por sexo.

Utilizámos a estrutura defendida por Nunes e Miranda (1969) para a composição social da população portuguesa.

Apresentámos, por isso, quatro classes diferentes ${ }^{8}$ :

- classe superior

- classe média

- classe inferior alta

- classe inferior baixa ${ }^{9}$.

\section{QUADRO VI}

Distribuição dos sujeitos do $9 .^{\circ}$ ano por classe social

\begin{tabular}{c|c|c|c|c|c|c|c|c|c|c}
\hline & \multicolumn{2}{|c|}{ C. SUP. } & \multicolumn{2}{c|}{ C. MED. } & \multicolumn{2}{c|}{ C. I. A. } & \multicolumn{2}{c|}{ C. I. B. } & \multicolumn{2}{c}{ TOTAL } \\
\cline { 2 - 9 } & $\mathrm{N}$ & $\%$ & $\mathrm{~N}$ & $\%$ & $\mathrm{~N}$ & $\%$ & $\mathrm{~N}$ & $\%$ & $\mathrm{~N}$ & $\%$ \\
\hline \multirow{2}{*}{ AMOSTRA } & 3 & 1,02 & 25 & 8,47 & 120 & 40,68 & 147 & 49,83 & 295 & 100,00 \\
\hline
\end{tabular}

Como podemos verificar, $1,02 \%$ dos sujeitos do $9 .^{\circ}$ ano de escolaridade pertencem à classe superior, $8,47 \%$ à classe média, $40,68 \%$ pertencem à classe inferior alta e 49,83\% à classe inferior baixa.

QUADRO VII

Distribuição dos sujeitos do $99^{\circ}$ ano por sexos

\begin{tabular}{l|r|r|r|r|r|r}
\hline & \multicolumn{2}{|c|}{ MASCULINO } & \multicolumn{2}{c|}{ FEMININO } & \multicolumn{2}{c}{ TOTAL } \\
\cline { 2 - 7 } & \multicolumn{1}{c|}{$\mathbf{N}$} & $\%$ & $\mathrm{~N}$ & \multicolumn{1}{c|}{$\%$} & $\mathrm{~N}$ & $\%$ \\
\hline \multirow{2}{*}{ AMOSTRA } & 127 & 43,05 & 168 & 56,95 & 295 & 100,00 \\
\hline
\end{tabular}


$\mathrm{Da}$ amostra $\left(9 .^{\circ}\right.$ ano) fazem parte $43,05 \%$ de sujeitos do sexo masculino e $56,95 \%$ do sexo feminino.

No questionário dos $11 . \% 122^{\circ}$ anos perguntámos em que classe social os jovens incluíam a sua família. Após a análise dos resultados do pré-questionário, sentimos a necessidade de sermos nós a distribuir os jovens dos $11 . \% 12 .^{\circ}$ anos pelas classes sociais, uma vez que os resultados obtidos, quando comparados com as condições económico-sociais e culturais do agregado, não correspondiam à realidade.

\section{QUADRO VIII}

Distribuição dos sujeitos dos $11 .^{\circ} / 12{ }^{\circ}$ anos por classe social

\begin{tabular}{c|c|c|c|c|c|c|c|c|c|c}
\hline & \multicolumn{2}{|c|}{ C. SUP. } & \multicolumn{2}{c|}{ C. MED. } & \multicolumn{2}{c|}{ C. I. A. } & \multicolumn{2}{c|}{ C. I. B. } & \multicolumn{2}{|c}{ TOTAL } \\
\cline { 2 - 10 } & $\mathrm{N}$ & $\%$ & $\mathrm{~N}$ & $\%$ & $\mathrm{~N}$ & $\%$ & $\mathrm{~N}$ & $\%$ & $\mathrm{~N}$ & $\%$ \\
\hline \multirow{2}{*}{ AMOSTRA } & 23 & 3,98 & 143 & 24,74 & 229 & 39,62 & 183 & 31,66 & 578 & 100,00 \\
\hline
\end{tabular}

Os alunos dos $11 . \% 12 .^{\circ}$ anos de escolaridade também estão distribuídos de forma desigual pelas quatro classes sociais. A classe com menor representação é a superior com apenas $3,98 \%$ dos sujeitos, seguida da classe média com $24,74 \%$. A classe com maior representação é a inferior alta, com $39,62 \%$, seguida da classe inferior baixa com $31,66 \%$.

\section{QUADRO IX}

Distribuição dos sujeitos dos $11 . \%^{\circ} / 1 .^{\circ}$ anos por sexos

\begin{tabular}{l|r|r|r|r|r|r}
\hline & \multicolumn{2}{|c|}{ MASCULINO } & \multicolumn{2}{c|}{ FEMININO } & \multicolumn{2}{c}{ TOTAL } \\
\cline { 2 - 7 } & $\mathrm{N}$ & \multicolumn{1}{c|}{$\%$} & $\mathrm{~N}$ & $\%$ & $\mathrm{~N}$ & $\%$ \\
\hline \multirow{2}{*}{ AMOSTRA } & 229 & 39,62 & 349 & 60,38 & 578 & 100,00 \\
\hline
\end{tabular}

A amostra (11. $\% 12 .^{\circ}$ anos) é constituída por $39,62 \%$ de sujeitos do sexo masculino e por $60,38 \%$ do sexo feminino.

\section{QUESTIONÁRIO DO 9. ANO - APURAMENTO DOS RESULTADOS - FREQUENCIAS ABSOLUTAS E RELATIVAS}

Neste ponto vamos analisar os dados recolhidos através do questionário respeitante aos sujeitos do $9 .^{\circ}$ ano de escolaridade. 
QUADRO X

Distribuição dos sujeitos por idades em função da classe social

\begin{tabular}{|c|c|c|c|c|c|c|c|c|c|c|}
\hline & \multicolumn{2}{|c|}{ C. SUP. } & \multicolumn{2}{|c|}{ C. MED. } & \multicolumn{2}{|c|}{ C. I. A. } & \multicolumn{2}{|c|}{ C. I. B. } & \multicolumn{2}{|c|}{ TOTAL } \\
\hline & $\mathrm{N}$ & $\%$ & $\mathrm{~N}$ & $\%$ & $\mathrm{~N}$ & $\%$ & $\mathrm{~N}$ & $\%$ & $\mathbf{N}$ & $\%$ \\
\hline 14 & 0 & 0,00 & 3 & 12,00 & 7 & 5,83 & 4 & 2,72 & 14 & 4,75 \\
\hline 15 & 3 & 100,00 & 17 & 68,00 & 45 & 37,50 & 45 & 30,61 & 110 & 37,29 \\
\hline 16 & 0 & 0,00 & 3 & 12,00 & 30 & 25,00 & 49 & 33,33 & 82 & 27,80 \\
\hline 17 & 0 & 0,00 & 0 & 0,00 & 23 & 19,17 & 28 & 19,05 & 51 & 17,29 \\
\hline 18 & 0 & 0,00 & 1 & 4,00 & 11 & 9,17 & 10 & 6,80 & 22 & 7,46 \\
\hline$>=19$ & 0 & 0,00 & 1 & 4,00 & 4 & 3,33 & 11 & 7,48 & 16 & 5,42 \\
\hline Não resposta & 0,00 & 0 & 0,00 & 0 & 0,00 & 0 & 0,00 & 0 & 0,00 & \\
\hline
\end{tabular}

Os sujeitos do $9 .^{\circ}$ ano que fazem parte da amostra têm idades compreendidas entre os 14 e os 21 anos de idade.

Podemos verificar pela análise do quadro que a classe superior é constituída apenas por sujeitos com 15 anos de idade, a classe média e inferior alta também têm uma grande percentagem de sujeitos com 15 anos de idade, $68,00 \%$ e $37,50 \%$, respectivamente.

A classe inferior baixa, embora tendo uma percentagem apreciável de sujeitos com 15 anos, é constituída na sua maioria por sujeitos com 16 anos $(33,33 \%)$.

QUADRO XI

Naturalidade dos sujeitos por classes sociais

\begin{tabular}{l|r|r|r|r|r|r|r|r|r|r}
\hline & \multicolumn{2}{|c|}{ C. SUP. } & \multicolumn{2}{c|}{ C. MED. } & \multicolumn{2}{c|}{ C. I. A. } & \multicolumn{2}{c|}{ C. I. B. } & \multicolumn{2}{c}{ TOTAL } \\
\cline { 2 - 10 } & $\mathrm{N}$ & \multicolumn{1}{c|}{$\%$} & $\mathrm{~N}$ & $\%$ & $\mathrm{~N}$ & $\%$ & $\mathrm{~N}$ & $\%$ & $\mathrm{~N}$ & $\%$ \\
\hline \multirow{2}{*}{ Portugal } & & & & & & & & & & \\
Ex-colónias & 3 & 100,00 & 22 & 88,00 & 100 & 83,33 & 116 & 78,91 & 241 & 81,69 \\
Estrangeiro & 0 & 0,00 & 3 & 12,00 & 6 & 5,00 & 5 & 3,40 & 14 & 4,75 \\
Não resposta & 0 & 0,00 & 0 & 0,00 & 14 & 11,67 & 26 & 17,69 & 40 & 13,56 \\
\hline
\end{tabular}

Os alunos do $9 .^{\circ}$ ano de escolaridade, que fazem parte da amostra, têm na sua maioria naturalidade portuguesa. Todos os alunos da classe superior são de naturalidade portuguesa. Na classe média, $88,00 \%$ e 12,00\% são naturais de Portugal e das ex-colónias, respectivamente.

Nas classes inferior alta e inferior baixa, embora na sua maioria sejam de naturalidade portuguesa, diminui a percentagem de alunos das ex-colónias e 128 aumenta a dos naturais do estrangeiro. 
QUADRO XII

Futuro escolar dos sujeitos das diferentes classes sociais

\begin{tabular}{l|r|r|r|r|r|r|r|r|r|r}
\hline & \multicolumn{2}{|c|}{ C. SUP. } & \multicolumn{2}{c|}{ C. MED. } & \multicolumn{2}{c|}{ C. I. A. } & \multicolumn{2}{c|}{ C. I. B. } & \multicolumn{2}{|c}{ TOTAL } \\
\cline { 2 - 9 } & $\mathrm{N}$ & \multicolumn{1}{c|}{$\%$} & $\mathrm{~N}$ & \multicolumn{1}{c}{$\%$} & \multicolumn{1}{c}{$\mathrm{N}$} & \multicolumn{1}{c}{$\%$} & $\mathrm{~N}$ & $\%$ & $\mathrm{~N}$ & $\%$ \\
\hline $\begin{array}{c}\text { Não cont. estudar } \\
\text { depois do 9. }\end{array}$ & 0 & 0,00 & 1 & 4,00 & 12 & 10,00 & 16 & 10,88 & 29 & 9,83 \\
$\begin{array}{c}\text { Não cont. est. depois } \\
\text { do 11. /12. }\end{array}$ & 0 & 0,00 & 1 & 4,00 & 26 & 21,67 & 42 & 28,57 & 69 & 23,39 \\
$\begin{array}{c}\text { Ingressar no ensino } \\
\text { superior }\end{array}$ & 3 & 100,00 & 23 & 92,00 & 82 & 68,33 & 89 & 60,54 & 197 & 66,78 \\
Não resposta & 0 & 0,00 & 0 & 0,00 & 0 & 0,00 & 0 & 0,00 & 0 & 0,00 \\
\hline
\end{tabular}

Todos os sujeitos da classe superior pretendem ingressar no ensino superior. Dos sujeitos da classe média, $92,00 \%$ pretendem ingressar no ensino superior, $4,00 \%$ pretendem deixar de estudar depois do $9 .^{\circ}$ ano e os restantes $4,00 \%$ pretendem deixar de estudar depois dos $11 .^{\circ} / 12 .^{\circ}$ anos. Em relação à classe inferior alta e à classe inferior baixa diminui a percentagem de sujeitos que pretendem ingressar no ensino superior e aumenta a percentagem de sujeitos que pretendem deixar de estudar depois de terminarem $09 .^{\circ}$ ano ou os $11 . \% 12 .^{\circ}$ anos.

QUADRO XIII

Razões apontadas pelos alunos das diferentes classes sociais para não continuarem a estudar

\begin{tabular}{|c|c|c|c|c|c|c|c|c|c|c|}
\hline & \multicolumn{2}{|c|}{ C. SUP. } & \multicolumn{2}{|c|}{ C. MED. } & \multicolumn{2}{|c|}{ C.I. A. } & \multicolumn{2}{|c|}{ C. I. B. } & \multicolumn{2}{|c|}{ TOTAL } \\
\hline & $\mathrm{N}$ & $\%$ & $\mathrm{~N}$ & $\%$ & $\mathrm{~N}$ & $\%$ & $\mathrm{~N}$ & $\%$ & $\mathrm{~N}$ & $\%$ \\
\hline $\begin{array}{l}\text { Dificuldades finan- } \\
\text { ceiras }\end{array}$ & 0 & 0,00 & 0 & 0,00 & 1 & 2,63 & 9 & 15,52 & 10 & 10,20 \\
\hline Vontade própria & 0 & 0,00 & 1 & 50,00 & 18 & 47,37 & 30 & 51,72 & 49 & 50,00 \\
\hline $\begin{array}{l}\text { Influencia dos am1- } \\
\text { gos }\end{array}$ & 0 & 0,00 & 0 & 0,00 & 0 & 0,00 & 2 & 3,45 & 2 & 2,04 \\
\hline $\begin{array}{l}\text { Imposição dos pais } \\
\text { Necessid. começar a }\end{array}$ & 0 & 0,00 & 0 & 0,00 & 1 & 2,63 & 2 & 3,45 & 3 & 3,06 \\
\hline $\begin{array}{l}\text { trabalhar } \\
\text { Já está cansado de }\end{array}$ & 0 & 0,00 & $\mathbf{0}$ & 0,00 & 2 & 5,26 & 11 & 18,97 & 13 & 13,27 \\
\hline $\begin{array}{l}\text { estudar } \\
\text { Está na hora tentar }\end{array}$ & 0 & 0,00 & 1 & 50,00 & 9 & 23,68 & 16 & 27,59 & 26 & 26,53 \\
\hline independência & 0 & 0,00 & 1 & 50,00 & 12 & 31,58 & 22 & 37,93 & 35 & 35,71 \\
\hline $\begin{array}{l}\text { Difícil ingressar no } \\
\text { ensino superior }\end{array}$ & 0 & 0,00 & 1 & 50,00 & 19 & 50,00 & 29 & 50,00 & 49 & 50,00 \\
\hline $\begin{array}{l}\text { Os cursos conhece } \\
\text { não despertam } \\
\text { interesse. }\end{array}$ & 0 & 0,00 & $\mathbf{0}$ & 0,00 & 1 & 2,63 & 5 & 8,62 & 6 & 6,12 \\
\hline $\begin{array}{l}\text { Um curso sup. não } \\
\text { é importante }\end{array}$ & 0 & 0,00 & 0 & 0,00 & 2 & 5,26 & 1 & 1,72 & 3 & 3,06 \\
\hline Outra(s) & 0 & 0,00 & 0 & 0,00 & 6 & 15,79 & 4 & 6,90 & 10 & 10,20 \\
\hline Não resposta & 0 & 0,00 & 0 & 0,00 & 0 & 0,00 & 1 & 1,72 & 1 & 1,02 \\
\hline
\end{tabular}


São várias as razões apontadas para os alunos deixarem de estudar. Podemos, no entanto, apontar duas que foram as mais escolhidas: vontade própria e dificuldade de ingresso no ensino superior.

\section{QUADRO XIV}

$O$ que pretendem fazer os sujeitos das diferentes classes sociais quando saírem da escola

\begin{tabular}{|c|c|c|c|c|c|c|c|c|c|c|}
\hline & \multicolumn{2}{|c|}{ C. SUP. } & \multicolumn{2}{|c|}{ C. MED. } & \multicolumn{2}{|c|}{ C. I. A. } & \multicolumn{2}{|c|}{ C. I. B. } & \multicolumn{2}{|c|}{ TOTAL } \\
\hline & $\mathbf{N}$ & $\%$ & $\mathrm{~N}$ & $\%$ & $\mathbf{N}$ & $\%$ & $\mathbf{N}$ & $\%$ & $\mathbf{N}$ & $\%$ \\
\hline Começar a trabalhar & 0 & 0,00 & 1 & 50,00 & 27 & 71,05 & 48 & 82,76 & 76 & 77,55 \\
\hline $\begin{array}{l}\text { Cumprir o serviço } \\
\text { militar }\end{array}$ & 0 & 0,00 & 1 & 50,00 & 2 & 5,26 & 3 & 5,17 & 6 & 6,12 \\
\hline Emigrar & 0 & 0,00 & 0 & 0,00 & 0 & 0,00 & 2 & 3,45 & 2 & 2,04 \\
\hline $\begin{array}{l}\text { Fazer um curso de } \\
\text { formação prof. }\end{array}$ & 0 & 0,00 & 0 & 0,00 & 9 & 23,68 & 5 & 8,62 & 14 & 14,29 \\
\hline Não resposta & 0 & 0,00 & 0 & 0,00 & 0 & 0,00 & 0 & 0,00 & 0 & 0,00 \\
\hline
\end{tabular}

Grande percentagem de sujeitos pretendem começar a trabalhar quando saírem da escola (valores que aumentam no sentido da classe média para a inferior baixa). Apenas alguns sujeitos da classe inferior alta e inferior baixa pretendem tirar um curso de formação profissional.

Com vista à análise dos dados respeitantes às profissões que os jovens gostariam de exercer, considerámos as categorias ou grupos de actividades profissionais referidos na Classificação Nacional de Profissões.

Apesar de termos considerado duas perguntas distintas no questionário, uma relativa à profissão que gostaria de exercer e outra relativa à actividade que gostaria de desenvolver, apenas apresentamos os dados relativos à profissão que gostariam de exercer. A pergunta, relativa à actividade que gostaria de desenvolver, foi considerada com a intenção de superar a ignorância que o sujeito poderia ter quanto à existência de tal ou tal profissão, estando no entanto consciente da actividade que gostaria de desenvolver. A actividade que gostaria de desenvolver permitiria posteriormente determinar qual a profissão desejada pelo jovem.

As profissões mais escolhidas ${ }^{10}$ pelos sujeitos da classe média, que não pretendem ingressar no ensino superior, são as referentes às Forças Armadas e à de Empregados de Escritório. Estas são também as profissões mais escolhidas pelos sujeitos da classe inferior alta e inferior baixa. $\mathrm{Na}$ classe inferior baixa é igual a percentagem de sujeitos que pretendem pertencer às Forças Armadas e de sujeitos que pretendem ser Agentes de Polícia. 


\section{QUADRO XV}

Razões por que continuam a estudar os sujeitos das diferentes classes sociais

\begin{tabular}{|c|c|c|c|c|c|c|c|c|c|c|}
\hline & \multicolumn{2}{|c|}{ C. SUP. } & \multicolumn{2}{|c|}{ C. MED. } & \multicolumn{2}{|c|}{ C. I. A. } & \multicolumn{2}{|c|}{ C. I. B. } & \multicolumn{2}{|c|}{ TOTAL } \\
\hline & $\mathbf{N}$ & $\%$ & $\mathbf{N}$ & $\%$ & $\mathbf{N}$ & $\%$ & $\mathbf{N}$ & $\%$ & $N$ & $\%$ \\
\hline Vontade própria & 3 & 100,00 & 16 & 66,67 & 70 & 64,81 & 88 & 67,18 & 177 & 66,54 \\
\hline Imposição dos pais & 0 & 0,00 & 4 & 16,67 & 3 & 2,78 & 12 & 9,16 & 19 & 7,14 \\
\hline $\begin{array}{l}\text { Influência dos ami- } \\
\text { gos }\end{array}$ & $\mathbf{0}$ & 0,00 & 0 & 0,00 & 0 & 0,00 & 8 & 6,11 & 8 & 3,01 \\
\hline $\begin{array}{l}\text { Estudos são impor- } \\
\text { tantes para a } \\
\text { pessoa }\end{array}$ & 2 & 66,67 & 20 & 83,33 & 73 & 67,59 & 97 & 74,05 & 192 & 72,18 \\
\hline $\begin{array}{l}\text { Para entrar no en- } \\
\text { sino superior }\end{array}$ & 1 & 33,33 & 15 & 62,50 & 41 & 37,96 & 49 & 37,40 & 106 & 39,85 \\
\hline $\begin{array}{l}\text { Ainda é novo para } \\
\text { sair da escola }\end{array}$ & 0 & 0,00 & 3 & 12,50 & 5 & 4,63 & 12 & 9,16 & 20 & 7,52 \\
\hline Outra(s) & 0 & 0,00 & 0 & 0,00 & 2 & 1,85 & 7 & 5,34 & 9 & 3,38 \\
\hline Não resposta & 0 & 0,00 & 0 & 0,00 & 0 & 0,00 & 0 & 0,00 & 0 & 0,00 \\
\hline
\end{tabular}

De acordo com os valores apresentados no quadro, os sujeitos da classe superior continuam a estudar depois do $9 .^{\circ}$ ano por vontade propria, porque os estudos são importantes e porque só assim poderão ingressar no ensino superior.

Os sujeitos da classe média apresentam como principal razão a da importância dos estudos para a pessoa; em segundo lugar a vontade própria e em terceiro lugar o facto de só continuando a estudar poderem ingressar no ensino superior.

Os sujeitos da classe inferior alta e inferior baixa apresentam as mesmas razões apontadas pelos sujeitos da classe média. Verifica-se no entanto uma diminuição da percentagem de sujeitos destas duas classes a justificarem a continuidade dos estudos pelo facto de só assim poderem ingressar no ensino superior. Tal facto poderá estar relacionado com a diminuição de sujeitos destas duas classes (sobretudo a classe inferior baixa) que não pretendem ingressar no ensino superior. 


\section{QUADRO XVI}

Área de estudos escolhida pelos sujeitos das diferentes classes sociais

\begin{tabular}{l|r|r|r|r|r|r|r|r|r|r}
\hline & \multicolumn{2}{|c|}{ C. SUP. } & \multicolumn{2}{c|}{ C. MED. } & \multicolumn{2}{c|}{ C. I. A. } & \multicolumn{2}{c|}{ C. I. B. } & \multicolumn{2}{c}{ TOTAL } \\
\cline { 2 - 11 } & \multicolumn{1}{c|}{$\mathrm{N}$} & \multicolumn{1}{c|}{ \% } & \multicolumn{1}{c|}{$\mathrm{N}$} & \multicolumn{1}{c|}{$\mathrm{N}$} & \multicolumn{1}{c}{$\%$} & $\mathrm{~N}$ & $\%$ & $\mathrm{~N}$ & $\%$ \\
\hline Científico-Naturais & 1 & 33,33 & 6 & 37,50 & 18 & 24,32 & 28 & 31,11 & 53 & 28,96 \\
Científico-Tecnoló- & & & & & & & & & & \\
$\quad$ gica & 1 & 33,33 & 2 & 12,50 & 6 & 8,11 & 14 & 15,56 & 23 & 12,57 \\
Económico-Sociais & 0 & 0,00 & 1 & 6,25 & 9 & 12,16 & 9 & 10,00 & 19 & 10,38 \\
Humanísticas & 0 & 0,00 & 5 & 31,25 & 27 & 36,49 & 28 & 31,11 & 60 & 32,79 \\
Artes Visuais & 1 & 33,33 & 0 & 0,00 & 5 & 6,76 & 1 & 1,11 & 7 & 3,83 \\
Técnico-Profissio- & & & & & & & & & & \\
$\quad$ nal & 0 & 0,00 & 0 & 0,00 & 5 & 6,76 & 5 & 5,56 & 10 & 5,46 \\
Desporto & 0 & 0,00 & 2 & 12,50 & 3 & 4,05 & 5 & 5,56 & 10 & 5,46 \\
Não resposta & 0 & 0,00 & 0 & 0,00 & 1 & 1,35 & 0 & 0,00 & 1 & 0,55 \\
\hline
\end{tabular}

Dos sujeitos da classe superior $33,33 \%$ optaram pela área de Científico-Naturais, 33,33\% pela área Científico-Tecnológica e outros 33,33\% optaram por Artes Visuais.

Em relação aos sujeitos da classe média, as áreas escolhidas foram Científico-Naturais $(37,50 \%)$ e Humanísticas $(31,25 \%)$, seguidas das de Desporto e Científico-Tecnológica com a mesma percentagem de escolhas (12,50\%). A área de Económico-Sociais foi apenas escolhida por $6,25 \%$ dos sujeitos

Relativamente à profissão escolhida pelos sujeitos das diferentes classes sociais que pretendem ingressar no ensino superior ${ }^{11}$, podemos verificar que $66,67 \%$ dos sujeitos da classe superior pretendem ser Arquitectos e 33,33\% pretendem ser Médicos.

Dos sujeitos da classe média, 21,74\% pretendem ser Professores do Ensino Secundário, 17,39\% querem ser Decoradores/Estilistas e 13,04\% Médicos.

Dos sujeitos da classe inferior alta, 21,95\% querem ser Professores do Ensino Secundário, $10,98 \%$ querem ser Advogados e outros $10.98 \%$ Gestores,

Dos sujeitos da classe inferior baixa $24,72 \%$ querem ser Professores do Ensino Secundário, 10,11\% Gestores e 7,87\% Médicos.

Os cursos do ensino superior mais escolhidos, em primeira opção ${ }^{12}$, pelos sujeitos da classe superior foram Arquitectura $(66,67 \%)$ e Medicina $(33,33 \%)$.

Pelos sujeitos da classe média, os mais escolhidos foram Design/Projecção Gráfica, História e Medicina com a mesma percentagem (13,04\%).

Pelos sujeitos da classe inferior alta os cursos do ensino superior mais escolhidos em primeiro lugar foram Direito $(10,98 \%)$, Gestão de Empresas $(9,76 \%) \mathrm{e}$ Medicina (8,54\%).

Pela classe inferior baixa os cursos mais escolhidos foram a Medicina $(8,99 \%)$, Economia $(7,87 \%)$, Direito e Gestão de Empresas com a mesma percentagem $(5,62 \%)$. 
Os cursos mais escolhidos em segunda opção ${ }^{13}$ pelos sujeitos da classe superior foram Design/Projecção Gráfica $(33,33 \%)$, Enfermagem $(33,33 \%)$ e História $(33,33 \%)$.

Pela classe média foram Gestão de Empresas $(13,04 \%)$ e Comunicação Social, Informática, Medicina e Arqueologia, cada um escolhido por 8,70\% dos sujeitos.

Pela classe inferior alta foram Medicina (10,98\%), Humanidades $(6,10 \%) \mathrm{e}$ Gestão de Empresas, Economia e Matemática, cada um escolhido por $4,88 \%$ dos sujeitos. Houve $9,76 \%$ de não respostas.

Relativamente à classe inferior baixa $12,36 \%$ escolheram Direito, $8,99 \%$ Contabilidade e Administração e 7,87\% Medicina. Houve 6,74\% de não respostas.

Os cursos mais escolhidos em terceira opção ${ }^{14}$ pelos sujeitos da classe superior foram os de Comunicação Social e Direito, cada um deles com 33,33\%, verificando-se também a mesma percentagem de não respostas.

Pela classe média foram Medicina (17,39\%) e Biologia, Educação Física, Línguas e Literaturas Clássicas, cada um deles com $8,70 \%$. Verificamos $13,04 \%$ de não respostas.

Pela classe inferior alta, os cursos mais escolhidos foram Comunicação Social, Economia, Línguas e Literaturas Clássicas e Química, cada um deles com $4,88 \%$ de escolhas. Verificamos $31,71 \%$ de não respostas.

Pela classe inferior baixa os cursos mais escolhidos foram Medicina $(7,87 \%)$, Informática $(5,62 \%)$ e Educadores de Infância $(4,49 \%)$. Verificamos $32,58 \%$ de não respostas.

De acordo com os valores apresentados, verificamos que aumentam as não respostas à medida que passamos da primeira à terceira opção.

Os cursos mais escolhidos em primeira opção ${ }^{15}$ pelos sujeitos do $9 .^{\circ}$ ano foram Medicina (9,64\%), Direito (8,12\%), Gestão de Empresas $(6,60 \%)$ e Informática $(5,08 \%)$.

Os cursos mais escolhidos em segunda opção ${ }^{16}$, pelos sujeitos do $9 .^{\circ}$ ano foram Medicina (9,14\%), Contabilidade e Administração e Direito com 6,09\% e Gestão de Empresas (5,58\%). Verificamos 7,11\% de não respostas.

Em terceira opção ${ }^{17}$, os cursos mais escolhidos pelos sujeitos do $9 .^{\circ}$ ano foram Medicina (6,60\%), Línguas e Literatura Clássica e Design/Projecção Gráfica, com igual percentagem de escolhas $(4,06 \%)$. Verificamos $29,95 \%$ de não respostas.

Da análise em termos globais verificamos que os sujeitos do $9 .^{\circ}$ ano apresentam maior percentagem de não respostas à medida que se passa da primeira para a terceira opção. 


\section{QUADRO XVII}

Razões por que escolheram o curso indicado em primeiro lugar os sujeitos das diferentes classes sociais

\begin{tabular}{|c|c|c|c|c|c|c|c|c|c|c|}
\hline & \multicolumn{2}{|c|}{ C. SUP. } & \multicolumn{2}{|c|}{ C. MED. } & \multicolumn{2}{|c|}{ C. I. A. } & \multicolumn{2}{|c|}{ C. I. B. } & \multicolumn{2}{|c|}{ TOTAL } \\
\hline & $\mathrm{N}$ & $\%$ & $\mathrm{~N}$ & $\%$ & $\mathrm{~N}$ & $\%$ & $\mathrm{~N}$ & $\%$ & $\mathbf{N}$ & $\%$ \\
\hline $\begin{array}{l}\text { Para se sentir reali- } \\
\text { zado }\end{array}$ & 3 & 100,00 & 18 & 78,26 & 56 & 68,29 & 59 & 66,29 & 136 & 69,04 \\
\hline $\begin{array}{l}\text { Curso com boa ima- } \\
\text { gem social }\end{array}$ & 0 & 0,00 & 4 & 17,39 & 14 & 17,07 & 18 & 20,22 & 36 & 18,27 \\
\hline $\begin{array}{l}\text { Curso aceite no mer- } \\
\text { cado de trabalho }\end{array}$ & 1 & 33,33 & 8 & 34,78 & 32 & 39,02 & 37 & 41,57 & 78 & 39,59 \\
\hline $\begin{array}{l}\text { Falta de licenciados } \\
\text { na área }\end{array}$ & 0 & 0,00 & 1 & 4,35 & 8 & 9,76 & 4 & 4,49 & 13 & 6,60 \\
\hline $\begin{array}{l}\text { Influência dos ami- } \\
\text { gos }\end{array}$ & 0 & 0,00 & 1 & 4,35 & 2 & 2,44 & 1 & 1,12 & 4 & 2,03 \\
\hline $\begin{array}{l}\text { Influência dos pais } \\
\text { Resp. imagem pré- }\end{array}$ & 0 & 0,00 & 2 & 8,70 & 3 & 3,66 & 3 & 3,37 & 8 & 4,06 \\
\hline -formada família & 0 & 0,00 & 1 & 4,35 & 2 & 2,44 & 6 & 6,74 & 9 & 4,57 \\
\hline $\begin{array}{l}\text { Respondeu testes psi- } \\
\text { cotécnicos }\end{array}$ & 0 & 0,00 & 0 & 0,00 & 3 & 3,66 & 2 & 2,25 & 5 & 2,54 \\
\hline Outra(s) & 0 & 0,00 & 5 & 21,74 & 11 & 13,41 & 18 & 20,22 & 34 & 17,26 \\
\hline Não resposta & 0 & 0,00 & 0 & 0,00 & 1 & 1,22 & 0 & 0,00 & 1 & 0,51 \\
\hline
\end{tabular}

Os sujeitos da classe superior gostariam de tirar o curso indicado em primeiro lugar para se sentirem realizados $(100,00 \%)$ e por ser um curso com boa aceitação no mercado de trabalho $(33,33 \%)$.

Relativamente aos sujeitos das classes média, inferior alta e inferior baixa gostariam de tirar o curso pelas mesmas razões apresentadas e pela mesma ordem de prioridades; para se sentirem realizados, por ser um curso com boa aceitação no mercado de trabalho e por ser um curso com boa imagem social.

Depois de analisarmos as preferências profissionais, os cursos escolhidos para o ingresso no ensino superior e as razões da sua escolha, seria interessante verificar se realmente os cursos são escolhidos de acordo com a profissão que cada jovem gostaria de exercer.

Chegámos à conclusão que nem sempre isso acontece. A título de exemplo, podemos verificar que nem todos os Arquitectos desejam tirar o curso de Arquitectura. Casos há de jovens que, desejando ser Arquitectos, escolhem em primeiro lugar o curso de Medicina, ou que, desejando ser Economistas, escolhem em primeiro lugar o curso de Línguas e Literaturas Clássicas. De acordo com estes dados, somos levados a crer que nem todos os jovens estão perfeitamente conscientes do curso superior que deverão frequentar para poderem exercer a profissão desejada. 


\section{QUADRO XVIII}

Ideia formada sobre a universidade onde gostariam de tirar o curso os sujeitos das diferentes classes sociais

\begin{tabular}{l|r|r|r|r|r|r|r|r|r|r}
\hline & \multicolumn{2}{|c|}{ C. SUP. } & \multicolumn{2}{c|}{ C. MED. } & \multicolumn{2}{c|}{ C. I. A. } & \multicolumn{2}{c|}{ C. I. B. } & \multicolumn{2}{c}{ TOTAL } \\
\cline { 2 - 10 } & \multicolumn{1}{c|}{$\mathrm{N}$} & \multicolumn{1}{c|}{$\%$} & \multicolumn{1}{c|}{ N } & \multicolumn{1}{c}{ N } & \multicolumn{1}{c}{ N } & $\%$ & N & $\%$ \\
\hline \multirow{2}{*}{ Sim } & & & & & & & & & & \\
Não & 3 & 100,00 & 8 & 34,78 & 25 & 30,49 & 34 & 38,20 & 70 & 35,53 \\
Não resposta & 0 & 0,00 & 15 & 65,22 & 57 & 69,51 & 55 & 61,80 & 127 & 64,47 \\
& 0 & 0,00 & 0 & 0,00 & 0 & 0,00 & 0 & 0,00 & 0 & 0,00 \\
\hline
\end{tabular}

Todos os sujeitos da classe superior sabem em que universidade gostariam de tirar o seu curso. Em relação às classes média, inferior alta e inferior baixa, são superiores a $60,00 \%$ as percentagens de sujeitos que não sabem em que universidade gostariam de tirar o seu curso.

Pretendemos também saber em que universidade os sujeitos das diferentes classes sociais gostariam de tirar o seu curso ${ }^{18}$.

Os sujeitos da classe superior escolheram as Universidades de Coimbra, Lisboa e Londres para tirar o curso.

Pelos sujeitos da classe média a universidade mais escolhida foi a de Coimbra (75,00\%), seguida pelas de Lisboa e Porto com igual percentagem (12,50\%).

Os sujeitos da classe inferior alta escolheram primeiro a Universidade de Coimbra $(40,00 \%)$, em segundo lugar a do Porto $(24,00 \%)$ e em terceiro lugar a de Lisboa $(16,00 \%)$. Seguem-se as Universidades de Aveiro, UCP-Viseu, Vila Real e o Conservatório com igual percentagem $(4,00 \%)$. Verificam-se $4,00 \%$ de não respostas.

Os sujeitos da classe inferior baixa escolheram em primeiro lugar a Universidade de Coimbra (52,94\%), em segundo a Escola Superior de Educação de Viseu $(14,71 \%)$, seguidas da Universidade de Lisboa e da UCP-Viseu, com igual percentagem $(8,82 \%)$.

As restantes Universidades escolhidas pelos sujeitos do $9 .^{\circ}$ ano que pretendem ingressar no ensino superior foram a do Porto (5,88\%), Instituto Superior de Educação Física (ISEF)-Lisboa e ISEF-Porto, com igual percentagem $(4,00 \%)$. Verificamos 2,94\% de não respostas.

Relativamente às razões por que os sujeitos das diferentes classes sociais escolheram a universidade onde gostariam de tirar o seu curso ${ }^{19}$, verificamos que os sujeitos da classe superior e da classe média escolheram a universidade pelo facto de ser o estabelecimento de ensino que oferece melhores condições e por estar mais próxima do mercado de trabalho.

A escolha dos sujeitos da classe inferior alta foi baseada no facto de ser o estabelecimento de ensino que oferece melhores condições e por estar na cidade que lhes oferece melhores condições e facilidades. Consideram também que a escolha está relacionada com a necessidade de realização pessoal, de independência e por gostarem de cidades grandes. Verificamos $4,00 \%$ de não respostas. 
As razões apresentadas pelos sujeitos da classe inferior baixa foram as mesmas, pela mesma ordem de prioridade; só não justificam a escolha com o facto de necessitarem de independência ou por gostarem de cidades grandes/desenvolvidas. Verificamos $2,94 \%$ de não respostas.

\section{QUADRO XIX}

Por que localização optaram os sujeitos das diferentes classes sociais

\begin{tabular}{|c|c|c|c|c|c|c|c|c|c|c|}
\hline & \multicolumn{2}{|c|}{ C. SUP. } & \multicolumn{2}{|c|}{ C. MED. } & \multicolumn{2}{|c|}{ C.I. A. } & \multicolumn{2}{|c|}{ C. I. B. } & \multicolumn{2}{|c|}{ TOTAL } \\
\hline & $\mathbf{N}$ & $\%$ & $\mathbf{N}$ & $\%$ & $\mathbf{N}$ & $\%$ & $\mathbf{N}$ & $\%$ & $\mathbf{N}$ & $\%$ \\
\hline Viseu & 1 & 33,33 & 7 & 30,43 & 47 & 57,32 & 54 & 60,67 & 109 & 55,33 \\
\hline Outra cidade & 2 & 66,67 & 16 & 69,57 & 35 & 42,68 & 35 & 39,33 & 88 & 44,67 \\
\hline Não resposta & 0 & 0,00 & 0 & 0,00 & 0 & 0,00 & 0 & 0,00 & 0 & 0,00 \\
\hline
\end{tabular}

Da classe superior apenas 33,33\% preferia tirar o curso em Viseu e $66,67 \%$ preferia ir para outra cidade.

Da classe média, 30,43\% preferia tirar o curso em Viseu e $69,57 \%$ preferia ir para outra cidade.

Da classe inferior alta, $57,32 \%$ preferia tirar o curso em Viseu e $42,68 \%$ preferia ir para outra cidade.

Em relação à classe inferior baixa $60,67 \%$ preferia tirar o curso em Viseu e $39,33 \%$ preferia ir para outra cidade.

Verificamos, portanto, que a percentagem de sujeitos que preferem tirar o curso em Viseu aumenta à medida que descemos na hierarquia das classes sociais.

Quanto à justificação da escolha em termos de localização ${ }^{20}$, verificamos que as razões apresentadas pelos sujeitos da classe superior têm a ver com o facto de se tratar de uma cidade onde dispõem de mais facilidades e por aí estar a universidade que garante melhores condições para tirar um curso.

Os sujeitos das restantes classes sociais justificam a escolha também pelo facto de lhes permitir estabelecer novas relações, por lhes permitir adquirir maior independência e por Viseu não ser o local mais indicado para tirar um curso superior.

Verificam-se algumas não respostas por parte destas três classes sociais. 


\section{QUADRO XX}

Por que universidade optaram os sujeitos das diferentes classes sociais

\begin{tabular}{|c|c|c|c|c|c|c|c|c|c|c|}
\hline & \multicolumn{2}{|c|}{ C. SUP. } & \multicolumn{2}{|c|}{ C. MED. } & \multicolumn{2}{|c|}{ C. I. A. } & \multicolumn{2}{|c|}{ C. I. B. } & \multicolumn{2}{|c|}{ TOTAL } \\
\hline & $\mathbf{N}$ & $\%$ & $\mathbf{N}$ & $\%$ & $\mathbf{N}$ & $\%$ & $\mathbf{N}$ & $\%$ & $\mathbf{N}$ & $\%$ \\
\hline Universid. Católica & 0 & 0,00 & 2 & 8,70 & 20 & 24,39 & 24 & 26,97 & 46 & 23,35 \\
\hline Universid. Privada & 0 & 0,00 & 2 & 8,70 & 10 & 12,20 & 9 & 10,11 & 21 & 10,66 \\
\hline Universid. Estatal & 3 & 100,00 & 19 & 82,61 & 52 & 63,41 & 56 & 62,92 & 130 & 65,99 \\
\hline Não resposta & 0 & 0,00 & $\mathbf{0}$ & 0,00 & 0 & 0,00 & 0 & 0,00 & 0 & 0,00 \\
\hline
\end{tabular}

Todos os sujeitos da classe superior escolheram a Universidade Estatal. Esta foi também escolhida po $82,61 \%$ de sujeitos da classe média, $63,41 \%$ da classe inferior alta e por $62,92 \%$ da classe inferior baixa.

A Universidade Católica foi escolhida por $8,70 \%$ de sujeitos da classe média, $24,39 \%$ da classe inferior e $26,97 \%$ da classe inferior baixa.

A Universidade Privada foi escolhida por $\mathbf{8 , 7 0 \%}$ dos sujeitos da classe média, $12,20 \%$ dos sujeitos da classe inferior alta e por $10,11 \%$ de sujeitos da classe inferior baixa.

Como podemos verificar, a percentagem superior de sujeitos que escolheram a Universidade Católica Portuguesa pertence à classe inferior baixa.

\section{QUADRO XXI}

Opgãa entre Viseu-UCP/Outra cidade-UE feita pelos sujeitos das diferentes classes sociais

\begin{tabular}{l|r|r|r|r|r|r|r|r|r|r}
\hline & \multicolumn{2}{|c|}{ C. SUP. } & \multicolumn{2}{c|}{ C. MED. } & \multicolumn{2}{c|}{ C. I. A. } & \multicolumn{2}{c|}{ C. I. B. } & \multicolumn{2}{c}{ TOTAL } \\
\cline { 2 - 10 } & $\mathrm{N}$ & \multicolumn{1}{c|}{$\%$} & \multicolumn{1}{c|}{$\mathrm{N}$} & \multicolumn{1}{c|}{$\%$} & $\mathrm{~N}$ & $\%$ & $\mathrm{~N}$ & $\%$ & $\mathrm{~N}$ & $\%$ \\
\hline Viseu-Universidade & & & & & & & & & & \\
$\quad$ Católica & 1 & 33,33 & 6 & 26,09 & 43 & 52,44 & 47 & 52,81 & 97 & 49,24 \\
Outra cidade-Univ. & & & & & & & & & & \\
Estatal & 2 & 66,67 & 17 & 73,91 & 39 & 47,56 & 42 & 47,19 & 100 & 50,76 \\
Não resposta & 0 & 0,00 & 0 & 0,00 & 0 & 0,00 & 0 & 0,00 & 0 & 0,00 \\
\hline
\end{tabular}

Preferiam ficar em Viseu na UCP $33,33 \%$ dos sujeitos da classe superior, 26,09\% da média, $52,44 \%$ da inferior alta e $52,81 \%$ da inferior baixa.

Preferiam ir para outra cidade, para a Universidade Estatal, $66,67 \%$ dos sujeitos da classe superior, $73,91 \%$ da média, $47,56 \%$ da inferior alta e $47,19 \%$ da inferior baixa. 
Verificamos que aumenta a percentagem de sujeitos que desejam ir para a UCP, ficando em Viseu, à medida que descemos na hierarquia das classes sociais.

Quanto à justificação da escolha ${ }^{21}$, verificamos que as razões apresentadas pelos sujeitos da classe superior foram as de ficar mais próximo de casa e de Viseu não dar possibilidade de emprego.

A classe média fez a escolha anterior apresentando como razões a da universidade que garante melhores condições de ingresso, porque ficava mais próximo de casa, por razões económicas e por ser a universidade que garante melhores condições para tirar um curso. Embora não correspondendo à mesma ordem de prioridades, estas foram também as razões apresentadas pelos sujeitos da classe inferior alta e pelos da classe inferior baixa.

A classe média apresenta $8,70 \%$ de não respostas e a classe inferior alta e inferior baixa $7,32 \%$ e $5,62 \%$, respectivamente.

\section{QUADRO XXII}

Centro da UCP por que optavam os sujeitos das diferentes classes sociais

\begin{tabular}{l|r|r|r|r|r|r|r|r|r|r}
\hline & \multicolumn{2}{|c|}{ C. SUP. } & \multicolumn{2}{c|}{ C. MED. } & \multicolumn{2}{c|}{ C. I. A. } & \multicolumn{2}{c|}{ C. I. B. } & \multicolumn{2}{c}{ TOTAL } \\
\cline { 2 - 10 } & \multicolumn{1}{c|}{$\mathrm{N}$} & \multicolumn{1}{c|}{ N } & \multicolumn{1}{c|}{$\%$} & $\mathrm{~N}$ & $\%$ & $\mathrm{~N}$ & $\%$ & $\mathrm{~N}$ & $\%$ \\
\hline Viseu & 1 & 33,33 & 14 & 60,87 & 51 & 62,20 & 61 & 68,54 & 127 & 64,47 \\
Braga & 0 & 0,00 & 0 & 0,00 & 1 & 1,22 & 2 & 2,25 & 3 & 1,52 \\
Lisboa & 1 & 33,33 & 5 & 21,74 & 19 & 23,17 & 16 & 17,98 & 41 & 20,81 \\
Porto & 1 & 33,33 & 4 & 17,39 & 11 & 13,41 & 9 & 10,11 & 25 & 12,69 \\
Não resposta & 0 & 0,00 & 0 & 0,00 & 0 & 0,00 & 1 & 1,12 & 1 & 0,51 \\
\hline
\end{tabular}

A UCP-Viseu, a UCP-Lisboa e a UCP-Porto foram escolhidas pela mesma percentagem de indivíduos da classe superior $(33,33 \%)$.

A UCP-Viseu foi escolhida por $60,87 \%$ de sujeitos da classe média, $62,20 \%$ da classe inferior alta e $68,54 \%$ da classe inferior baixa.

A UCP-Lisboa foi escolhida por $21,74 \%$ de sujeitos da classe média, $62,20 \%$ da classe inferior alta e por $17,98 \%$ da classe inferior baixa.

A UCP-Porto foi escolhida por $17,39 \%$ de sujeitos da classe média, $13,41 \%$ da classe inferior alta e $10,11 \%$ da classe inferior baixa.

A UCP-Braga não foi escolhida por nenhum sujeito da classe média, e foi escolhida apenas por $1,22 \%$ de sujeitos da classe inferior alta e por $2,25 \%$ da inferior baixa. Verificamos $1,12 \%$ de não respostas da classe inferior baixa. 
Quanto à justificação da escolha ${ }^{22}$, verificamos que as razões apontadas pelos sujeitos da classe superior para a escolha anterior foram o facto de poderem ficar mais perto de casa, por ser a cidade que lhes oferece melhores condições e melhor mercado de trabalho.

As duas primeiras razões foram sempre também as mais apontadas pelos sujeitos das outras classes sociais.

Os sujeitos da classe média e da classe inferior baixa apresentam como terceira razão o facto de se tratar de uma universidade que garante as melhores condições para tirar um curso e a classe inferior alta por se desejar estabelecer novas relações. Verificamos $1,12 \%$ de não respostas para a classe inferior baixa.

\section{QUESTIONÁRIO DOS $11.0^{\circ} 12 .^{\circ}$ ANOS - APURAMENTO DOS RESUL- TADOS - FREQUÊNCIAS ABSOLUTAS E RELATIVAS}

Neste ponto vamos analisar os dados recolhidos através do questionário respeitante aos sujeitos dos $11 . \% 12 .^{\circ}$ anos de escolaridade.

\section{QUADRO XXIII}

Distribuição dos sujeitos por idades em função da classe social

\begin{tabular}{|c|c|c|c|c|c|c|c|c|c|c|}
\hline & & & & MED. & & & & & & rAL \\
\hline & $\mathrm{N}$ & $\%$ & $\mathbf{N}$ & $\%$ & $\mathbf{N}$ & $\%$ & $\mathbf{N}$ & $\%$ & $\mathbf{N}$ & $\%$ \\
\hline 16 & 2 & 8,70 & 13 & 9,09 & 11 & 4,80 & 7 & 3,83 & 33 & 5,71 \\
\hline 17 & 7 & 30,43 & 41 & 28,67 & 53 & 23,14 & 20 & 10,93 & 121 & 20,93 \\
\hline 18 & 10 & 43,48 & 41 & 28,67 & 66 & 28,82 & 61 & 33,33 & 178 & 30,80 \\
\hline 19 & 3 & 13,04 & 19 & 13,29 & 41 & 17,90 & 34 & 18,58 & 97 & 16,78 \\
\hline 20 & 1 & 4,35 & 17 & 11,89 & 27 & 11,79 & 33 & 18,03 & 78 & 13,49 \\
\hline 21 & 0 & 0,00 & 7 & 4,90 & 15 & 6,55 & 13 & 7,10 & 35 & 6,06 \\
\hline$>=22$ & 0 & 0,00 & 5 & 3,50 & 16 & 6,99 & 15 & 8,20 & 36 & 6,23 \\
\hline Não resposta & 0 & 0,00 & 0 & 0,00 & 0 & 0,00 & 0 & 0,00 & 0 & 0,00 \\
\hline
\end{tabular}

Os sujeitos dos $11 . \%^{\circ} 12 .^{\circ}$ anos da amostra têm idades compreendidas entre os 16 e os 40 anos de idade. Interessa salientar, da análise do quadro, que a classe superior só tem sujeitos até aos vinte anos de idade. Nesta classe a idade que concentra maior percentagem de sujeitos é a dos 18 anos $(43,48 \%)$, seguida da dos 17 anos $(30,43 \%)$.

Atente-se na subida percentual das idades dos sujeitos quando nos deslocamos da classe superior para a classe inferior baixa. 


\section{QUADRO XXIV}

Naturalidade dos sujeitos por classes sociais

\begin{tabular}{l|r|r|r|r|r|r|r|r|r|r}
\hline & \multicolumn{2}{|c|}{ C. SUP. } & \multicolumn{2}{c|}{ C. MED. } & \multicolumn{2}{c|}{ C. I. A. } & \multicolumn{2}{c|}{ C. I. B. } & \multicolumn{2}{c}{ TOTAL } \\
\cline { 2 - 9 } & \multicolumn{1}{c|}{$\mathrm{N}$} & \multicolumn{1}{c|}{$\%$} & \multicolumn{1}{c}{$\mathrm{N}$} & \multicolumn{1}{c}{$\%$} & $\mathrm{~N}$ & \multicolumn{1}{c}{$\%$} & $\mathrm{~N}$ & \multicolumn{1}{c}{$\%$} & $\mathrm{~N}$ & $\%$ \\
\hline \multirow{3}{*}{ Portugal } & & & & & & & & & & \\
Ex-colónias & 21 & 91,30 & 109 & 76,22 & 154 & 67,25 & 133 & 72,68 & 417 & 72,15 \\
Estrangeiro & 2 & 8,70 & 26 & 18,18 & 40 & 17,47 & 25 & 13,66 & 93 & 16,09 \\
Não resposta & 0 & 0,00 & 8 & 5,59 & 35 & 15,28 & 25 & 13,66 & 68 & 11,76 \\
& 0 & 0,00 & 0 & 0,00 & 0 & 0,00 & 0 & 0,00 & 0 & 0,00 \\
\hline
\end{tabular}

Podemos verificar pela análise do quadro que os sujeitos dos $11 . \% 12 .^{\circ}$ anos da classe superior são na grande maioria $(91,30 \%)$ de naturalidade portuguesa e apenas uma pequena percentagem é natural das ex-colónias $(8,70 \%)$.

$\mathrm{Na}$ classe média são na sua maioria de naturalidade portuguesa mas aumenta $\mathrm{o}$ número de sujeitos das ex-colónias e de naturalidade estrangeira; o mesmo acontece em relação aos sujeitos da classe inferior alta. A classe inferior baixa apresenta também uma grande percentagem de sujeitos de naturalidade portuguesa, mas apresenta igual número de sujeitos das ex-colónias e naturais de países estrangeiros.

\section{QUADRO XXV}

Futuro escolar dos sujeitos das diferentes classes sociais

\begin{tabular}{l|r|r|r|r|r|r|r|r|r|r}
\hline & \multicolumn{2}{|c|}{ C. SUP. } & \multicolumn{2}{c|}{ C. MED. } & \multicolumn{2}{c|}{ C. I. A. } & \multicolumn{2}{c|}{ C. I. B. } & \multicolumn{2}{|c}{ TOTAL } \\
\cline { 2 - 9 } & $\mathrm{N}$ & \multicolumn{1}{c|}{$\%$} & \multicolumn{1}{c|}{$\mathrm{N}$} & \multicolumn{1}{c}{$\%$} & $\mathrm{~N}$ & \multicolumn{1}{c}{$\%$} & $\mathrm{~N}$ & \multicolumn{1}{c}{$\%$} & $\mathrm{~N}$ & $\%$ \\
\hline Ingressar no ensino & & & & & & & & & & \\
superior & 23 & 100,00 & 139 & 97,20 & 196 & 85,59 & 136 & 74,32 & 494 & 85,47 \\
Não ingressar no en- & & & & & & & & & & \\
sino superior & 0 & 0,00 & 4 & 2,80 & 33 & 14,41 & 47 & 25,68 & 84 & 14,53 \\
Não resposta & 0 & 0,00 & 0 & 0,00 & 0 & 0,00 & 0 & 0,00 & 0 & 0,00 \\
\hline
\end{tabular}

Como podemos verificar todos os sujeitos da classe superior pretendem ingressar no ensino superior. Esta percentagem vai diminuindo ao percorrer a hierarquia das classes sociais, apresentando a classe inferior baixa a menor percentagem de sujeitos que pretendem ingressar no ensino superior e a maior percentagem dos que não pretendem ingressar no ensino superior. 


\section{QUADRO XXVI}

Razões apontadas pelos alunos das diferentes classes sociais para não continuarem a estudar

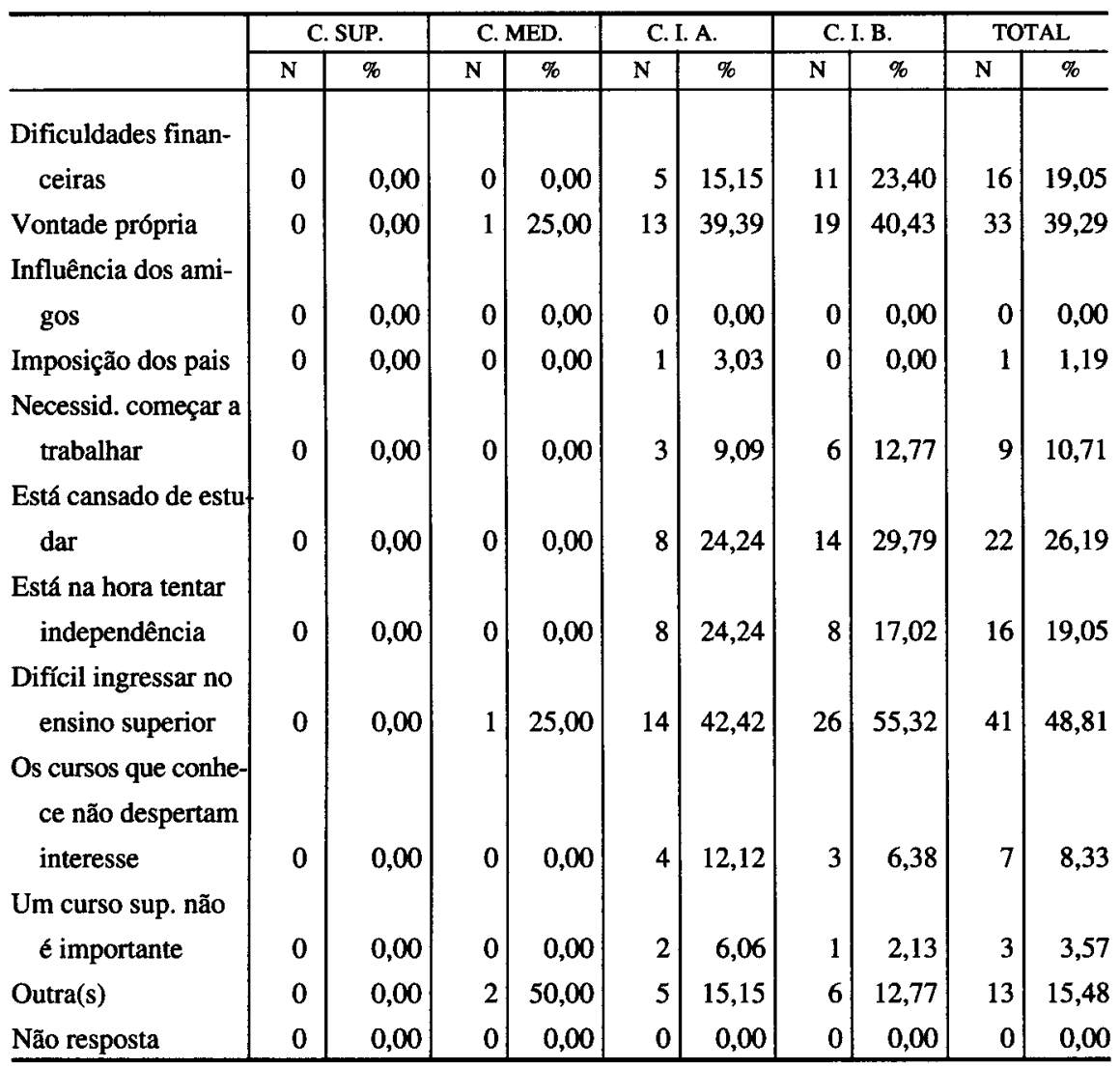

Os sujeitos da classe média apontam, de igual forma, como razões para não continuarem a estudar, a vontade própria e a dificuldade de ingresso no ensino superior $(25,00 \%) ; 50,00 \%$ apontam outras razões não especificadas.

Para os sujeitos da classe inferior alta e inferior baixa, a escolha recaiu prioritariamente na dificuldade de acesso ao ensino superior e posteriormente na vontade própria. 
QUADRO XXVII

$\mathrm{O}$ que pretendem fazer os sujeitos das diferentes classes sociais quando saírem da escola

\begin{tabular}{l|r|r|r|r|r|r|r|r|r|r}
\hline & \multicolumn{2}{|c|}{ C. SUP. } & \multicolumn{2}{c|}{ C. MED. } & \multicolumn{2}{c|}{ C. I. A. } & \multicolumn{2}{c|}{ C. I. B. } & \multicolumn{2}{c}{ TOTAL } \\
\cline { 2 - 9 } & $\mathrm{N}$ & \multicolumn{1}{c|}{$\%$} & \multicolumn{1}{c|}{$\mathrm{N}$} & \multicolumn{1}{c}{$\%$} & $\mathrm{~N}$ & \multicolumn{1}{c}{$\%$} & $\mathrm{~N}$ & $\%$ & $\mathrm{~N}$ & $\%$ \\
\hline Começar a trabalhar & 0 & 0,00 & 2 & 50,00 & 21 & 63,64 & 36 & 76,60 & 59 & 70,24 \\
Cumprir o serviço & & & & & & & & & & \\
$\quad$ militar & 0 & 0,00 & 2 & 50,00 & 8 & 24,24 & 3 & 6,38 & 13 & 15,48 \\
Emigrar & 0 & 0,00 & 0 & 0,00 & 0 & 0,00 & 1 & 2,13 & 1 & 1,19 \\
Fazer um curso de & & & & & & & & & & \\
$\quad$ formação prof. & 0 & 0,00 & 0 & 0,00 & 4 & 12,12 & 6 & 12,77 & 10 & 11,90 \\
Não resposta & 0 & 0,00 & 0 & 0,00 & 0 & 0,00 & 1 & 2,13 & 1 & 1,19 \\
\hline
\end{tabular}

Quando saírem da escola os sujeitos da classe média pretendem começar a trabalhar ou cumprir o serviço militar. Os sujeitos da classe alta desejam começar a trabalhar e, em segundo lugar, cumprir o serviço militar. Os sujeitos da classe inferior baixa pretendem começar a trabalhar e, em segundo lugar, tirar um curso de formação profissional.

De acordo com os dados obtidos ${ }^{23}$, podemos verificar que $50,00 \%$ dos sujeitos da classe média, que não pretendem continuar a estudar, querem entrar para as Forças Armadas e 25,00\% pretendem ser Empregados de Escritório. Da classe inferior alta, $18,18 \%$ pretendem ser Auxiliares de Educação Infantil e $15,15 \%$ pretendem entrar nas Forças Armadas, sendo estas as profissões mais escolhidas. Dos sujeitos da classe inferior baixa 34,04\% pretendem ser Empregados de Escritório, tendo sido escolhidas, em segundo lugar, pelo mesmo número de pessoas, as profissões de Auxiliar de Educação Infantil e de Técnico de Informática.

Relativamente à profissão escolhida pelos jovens que pretendem ingressar no ensino superior ${ }^{24}$, os sujeitos da classe superior preferem ser Médicos ou Advogados.

Da classe média, os sujeitos escolhem em primeiro lugar a profissão de Gestor e em segundo lugar a de Médico.

Os sujeitos da classe inferior alta preferem em maior percentagem ser Professores do Ensino Secundário e, em seguida, Médicos.

No que diz respeito aos sujeitos da classe inferior baixa, estes preferem em primeiro lugar ser Professores do Ensino Secundário e em segundo lugar Gestores de Empresas.

Os cursos do ensino superior mais escolhidos, em primeira opção ${ }^{25}$, pelos sujeitos da classe superior foram Medicina (21,74\%), Direito $(13,04 \%)$ e, com igual percentagem, $(8,70 \%)$ os cursos de Sociologia, Relações Internacionais e Comunicação Social. 
Pelos sujeitos da classe média foram escolhidos Economia (10,79\%), Gestão de Empresas e Medicina, com igual percentagem (9,35\%).

Em relação à classe inferior alta, os cursos mais escolhidos, em primeiro lugar, foram Economia (9,18\%), Medicina $(7,14 \%)$ e Enfermagem $(5,10 \%)$. Pelos sujeitos da classe inferior baixa foram preferidos Gestão de Empresas $(10,29 \%)$, Medicina $(7,35 \%)$ e Relações Internacionais Públicas.

A percentagem de não respostas foi baixa: $0,51 \%$ na classe inferior alta e $2,21 \%$ na classe inferior baixa.

Relativamente à segunda opção ${ }^{26}$, os cursos mais escolhidos pelos sujeitos da classe superior foram Biologia (13,04\%), Design, Projecção Gráfica, Economia e Relações Internacionais Públicas, com a mesma percentagem $(8,70 \%)$. Verificamos $13,04 \%$ de não respostas.

Os cursos mais escolhidos pelos sujeitos da classe média foram Gestão de Empresas (9,35\%), Relações Internacionais Públicas (8,63\%) e Economia $(7,91 \%)$. Verificamos $5,75 \%$ de não respostas.

Pelos sujeitos da classe inferior alta os cursos mais escolhidos foram Gestão de Empresas $(8,16 \%)$, Relações Internacionais Públicas $(6,12 \%)$ e Informática $(5,10 \%)$. Verificamos $3,06 \%$ de não respostas.

Os cursos mais escolhidos pela classe inferior baixa foram Economia $(7,35 \%)$, Educadores de Infância e Biologia, com a mesma percentagem $(5,15 \%)$. Verificamos $7,35 \%$ de não respostas.

Relativamente à terceira opção ${ }^{27}$, os cursos mais escolhidos pelos sujeitos da classe superior foram Direito e Gestão de Empresas, com a mesma percentagem $(8,70 \%)$. Verificamos $17,39 \%$ de não respostas.

Pelos sujeitos da classe média os cursos mais escolhidos foram Direito (5,76\%), Relações Internacionais Públicas (5,04\%) e Gestão de Empresas $(4,32 \%)$. Verificamos $20,86 \%$ de não respostas.

Os cursos mais escolhidos pelos sujeitos da classe inferior alta foram, com a mesma percentagem $(4,08 \%)$, Enfermagem, Relações Internacionais Públicas, Contabilidade e Administração. Verificamos 16,33\% de não respostas.

Os cursos mais escolhidos pelos sujeitos da classe inferior baixa foram Informática $(5,88 \%)$, Direito $(5,15 \%)$, Gestão de Empresas, Contabilidade e Administração com a mesma percentagem $(4,41 \%)$. Verificamos $22,06 \%$ de não respostas.

Verificamos um aumento de não respostas à medida que passamos da primeira para a terceira opção.

Os cursos mais escolhidos, em primeira opçãa ${ }^{28}$, pelos sujeitos dos $11 .^{\circ} 12 .^{\circ}$ anos de escolaridade, foram Medicina (8,50\%), Economia e Gestão de Empresas com a mesma percentagem $(7,49 \%)$. Verificamos $0,81 \%$ de não respostas. Relativamente à segunda opção ${ }^{29}$, os cursos mais escolhidos foram Gestão de Empresas $(7,49 \%)$, Relações Internacionais Públicas $(5,87 \%)$ e Economia $(5,26 \%)$. Verificamos $5,47 \%$ de não respostas. 
Relativamente à terceira opção ${ }^{30}$, os cursos mais escolhidos foram Direito (4,86\%), Contabilidade e Administração (4,66\%) e Gestão de Empresas (4,05\%). Verificamos $19,23 \%$ de não respostas.

O número de não respostas vai aumentando à medida que passamos da primeira à terceira opção.

\section{QUADRO XXVIII}

Razões por que escolheram o curso indicado em primeiro lugar os sujeitos das diferentes classes sociais

\begin{tabular}{|c|c|c|c|c|c|c|c|c|c|c|}
\hline & \multicolumn{2}{|c|}{ c. SUP. } & \multicolumn{2}{|c|}{ C. MED. } & \multicolumn{2}{|c|}{ C. I. A. } & \multicolumn{2}{|c|}{ C. I. B. } & \multicolumn{2}{|c|}{ TOTAL } \\
\hline & $\mathbf{N}$ & $\%$ & $\mathbf{N}$ & $\%$ & $\mathbf{N}$ & $\%$ & $\mathbf{N}$ & $\%$ & $\mathrm{~N}$ & $\%$ \\
\hline Para se sentir reali- & & & & & & & & & & \\
\hline zado & 19 & 82,61 & 108 & 77,70 & 168 & 85,71 & 98 & 72,06 & 393 & 79,55 \\
\hline Curso com boa ima- & & & & & & & & & & \\
\hline gem social & 5 & 21,74 & 17 & 12,23 & 28 & 14,29 & 23 & 16,91 & 73 & 14,78 \\
\hline Curso aceite no mer & & & & & & & & & & \\
\hline cado trabalho & 6 & 26,09 & 56 & 40,29 & 72 & 36,73 & 57 & 41,91 & 191 & 38,66 \\
\hline Falta de licenciados & & & & & & & & & & \\
\hline na área & 2 & 8,70 & 6 & 4,32 & 15 & 7,65 & 23 & 16,91 & 46 & 9,31 \\
\hline Influência dos ami- & & & & & & & & & & \\
\hline gos & 1 & 4,35 & 2 & 1,44 & 1 & 0,51 & 4 & 2,94 & 8 & 1,62 \\
\hline Influência dos pais & 0 & 0,00 & 2 & 1,44 & 8 & 4,08 & 2 & 1,47 & 12 & 2,43 \\
\hline Resp. imagem pre- & & & & & & & & & & \\
\hline -formada família & 1 & 4,35 & 8 & 5,76 & 7 & 3,57 & 3 & 2,21 & 19 & 3,85 \\
\hline Respondeu testes & & & & & & & & & & \\
\hline psicotécnicos & 5 & 21,74 & 11 & 7,91 & 7 & 3,57 & 3 & 2,21 & 26 & 5,26 \\
\hline Outra(s) & 5 & 21,74 & 44 & 31,65 & 41 & 20,92 & 27 & 19,85 & 117 & 23,68 \\
\hline Não resposta & 0 & 0,00 & 0 & 0,00 & 1 & 0,51 & 3 & 2,21 & 4 & 0,81 \\
\hline
\end{tabular}

Para além de apresentarem outras razões, os sujeitos das quatro classes sociais gostariam de tirar o curso indicado, em primeiro lugar, para se sentirem realizados e por ser um curso com boa aceitação no mercado de trabalho. 


\section{QUADRO XXIX}

Ideia formada sobre a universidade onde gostariam de tirar o curso os sujeitos das diferentes classes sociais

\begin{tabular}{|c|c|c|c|c|c|c|c|c|c|c|}
\hline & \multicolumn{2}{|c|}{ C. SUP. } & \multicolumn{2}{|c|}{ C. MED. } & \multicolumn{2}{|c|}{ C. I. A. } & \multicolumn{2}{|c|}{ C. I. B. } & \multicolumn{2}{|c|}{ TOTAL } \\
\hline & $\mathbf{N}$ & $\%$ & $\mathrm{~N}$ & $\%$ & $\mathrm{~N}$ & $\%$ & $\mathrm{~N}$ & $\%$ & $\mathbf{N}$ & $\%$ \\
\hline Sim & 19 & 82,61 & 89 & 64,03 & 103 & 52,55 & 69 & 50,74 & 280 & 56,68 \\
\hline Não & 4 & 17,39 & 50 & 35,97 & 92 & 46,94 & 65 & 47,79 & 211 & 42,71 \\
\hline Não resposta & 0 & 0,00 & 0 & 0,00 & 1 & 0,51 & 2 & 1,47 & 3 & 0,61 \\
\hline
\end{tabular}

Sabem em que universidade gostariam de tirar o seu curso $82,61 \%$ de sujeitos da classe superior, $64,03 \%$ da classe média, $52,55 \%$ da classe inferior alta e $50,74 \%$ da classe inferior baixa.

Pretendemos também saber em que universidade os sujeitos das diferentes classes sociais gostariam de tirar o seu curso ${ }^{31}$.

As universidades mais escolhidas pelos sujeitos da classe superior foram a Universidade de Coimbra $(63,16 \%)$, a do Porto e a de Lisboa, todas com a mesma percentagem $(10,53 \%)$.

$\mathrm{Na}$ classe média, as universidades mais escolhidas foram a Universidade de Coimbra $(30,34 \%)$, a do Porto $(17,98 \%)$ e a de Lisboa $(13,48 \%)$.

Pelos sujeitos da classe inferior alta, foram a Universidade de Coimbra $(28,16 \%)$, a ESE-Viseu $(18,45 \%)$ e a Universidade de Lisboa $(13,59 \%)$.

As duas primeiras universidades escolhidas pela classe inferior alta foram também as escolhidas pela classe inferior baixa, tendo mencionado em terceiro lugar a Universidade do Porto $(14,49 \%)$. Verificamos ainda algumas não respostas.

Quanto às razões apresentadas para tal escolha ${ }^{32}$, salientamos que os sujeitos das diferentes classes escolheram a universidade por ser um estabelecimento de ensino que oferece as melhores condições de formação e pelo facto de estar situada numa cidade onde dispõem de melhores condições e facilidades.

\section{QUADRO XXX}

Por que localização optaram os sujeitos das diferentes classes sociais

\begin{tabular}{l|r|r|r|r|r|r|r|r|r|r}
\hline & \multicolumn{2}{|c|}{ C. SUP. } & \multicolumn{2}{c|}{ C. MED. } & \multicolumn{2}{c|}{ C. I. A. } & \multicolumn{2}{c|}{ C. I. B. } & \multicolumn{2}{c}{ TOTAL } \\
\cline { 2 - 10 } & \multicolumn{1}{|c|}{$\mathrm{N}$} & \multicolumn{1}{c|}{ N } & \multicolumn{1}{c|}{$\%$} & N & \% & N & $\%$ & N & $\%$ \\
\hline \multirow{2}{*}{ Viseu } & & & & & & & & & & \\
Outra cidade & 1 & 4,35 & 35 & 25,18 & 86 & 43,88 & 73 & 53,68 & 195 & 39,47 \\
Não resposta & 22 & 95,65 & 103 & 74,10 & 108 & 55,10 & 61 & 44,85 & 294 & 59,51 \\
& 0 & 0,00 & 1 & 0,72 & 2 & 1,02 & 2 & 1,47 & 5 & 1,01 \\
\hline
\end{tabular}


A percentagem de sujeitos que optava por ficar em Viseu aumenta à medida que descemos na hierarquia das classes sociais. Assim, preferiam ficar em Viseu $4,35 \%$ dos sujeitos da classe superior, $25,18 \%$ de sujeitos da classe média, $43,88 \%$ da classe inferior alta e $53,68 \%$ da classe inferior baixa.

Quanto à justificação da escolha em termos de localização ${ }^{33}$, verificamos que os sujeitos da classe superior justificaram a sua escolha, sobretudo, por assim lhes ser permitido estabelecer novas relações $(39,13 \%)$, por gostarem do ambiente da cidade e por se localizar lá a universidade que garante melhores condições para tirar um curso. Verificamos $13,04 \%$ de não respostas.

As justificações apresentadas pelos sujeitos da classe média foram, sobretudo, o facto de assim poderem estabelecer novas relações $(28,06 \%)$ e por disporem das melhores facilidades no local $(20,86 \%)$; consideram também que Viseu não é o local mais indicado para tirar um curso $(12,23 \%)$. Verificamos $21,58 \%$ de não respostas.

As razões mais apontadas pelos sujeitos da classe inferior alta foram o facto de disporem na cidade de mais facilidades $(39,80 \%)$, por poderem estabelecer novas relações $(23,98 \%)$ e porque Viseu não é o local mais indicado para tirar um curso. Verificamos $10,71 \%$ de não respostas.

As duas primeiras razões apresentadas pelos sujeitos da classe inferior alta foram-no, também, pelos sujeitos da classe inferior baixa com $51,47 \%$ e $19,85 \%$, respectivamente. A terceira razão mais apontada pelos sujeitos da classe inferior baixa foi o facto de estar nessa cidade a universidade que garante melhores condições para tirar um curso. Verificamos $14,71 \%$ de não respostas.

\section{QUADRO XXXI}

Por que universidade optaram os sujeitos das diferentes classes sociais

\begin{tabular}{l|r|r|r|r|r|r|r|r|r|r}
\hline & \multicolumn{2}{|c|}{ C. SUP. } & \multicolumn{2}{c|}{ C. MED. } & \multicolumn{2}{c|}{ C. I. A. } & \multicolumn{2}{c|}{ C. I. B. } & \multicolumn{2}{c}{ TOTAL } \\
\cline { 2 - 10 } & \multicolumn{1}{|c|}{$\mathrm{N}$} & \multicolumn{1}{c|}{$\mathrm{N}$} & \multicolumn{1}{c|}{$\%$} & \multicolumn{1}{c}{$\mathrm{N}$} & $\%$ & $\mathrm{~N}$ & $\%$ & $\mathrm{~N}$ & $\%$ \\
\hline Universid. Católica & 0 & 0,00 & 15 & 10,79 & 20 & 10,20 & 14 & 10,29 & 49 & 9,92 \\
Universid. Privada & 1 & 4,35 & 12 & 8,63 & 8 & 4,08 & 8 & 5,88 & 29 & 5,87 \\
Universid. Estatal & 22 & 95,65 & 112 & 80,58 & 167 & 85,20 & 112 & 82,35 & 413 & 83,60 \\
Não resposta & 0 & 0,00 & 0 & 0,00 & 1 & 0,51 & 2 & 1,47 & 3 & 0,61 \\
\hline
\end{tabular}

Escolheram a Universidade Católica, 10,79\% de sujeitos da classe média, $10,20 \%$ da classe inferior alta e $10,29 \%$ da classe inferior baixa.

Escolheram a Universidade Privada, 4,35\% de sujeitos da classe superior, $8,63 \%$ da classe média, $4,08 \%$ da classe inferior alta e $5,88 \%$ da classe inferior 146 baixa. 
Escolheram a Universidade Estatal, 95,65\% de sujeitos da classe superior, $80,58 \%$ de sujeitos da classe média, $85,20 \%$ da classe inferior alta e $82,35 \%$ da classe inferior baixa.

Como podemos verificar as universidades mais escolhidas foram a Estatal, seguida da Universidade Católica.

\section{QUADRO XXXII}

Opção entre Viseu-UCP/Outra cidade-UE feita pelos sujeitos das diferentes classes sociais

\begin{tabular}{l|r|r|r|r|r|r|r|r|r|r}
\hline & \multicolumn{2}{|c|}{ C. SUP. } & \multicolumn{2}{c|}{ C. MED. } & \multicolumn{2}{c|}{ C. I. A. } & \multicolumn{2}{c|}{ C. I. B. } & \multicolumn{2}{c}{ TOTAL } \\
\cline { 2 - 9 } & $\mathrm{N}$ & \multicolumn{1}{c|}{$\%$} & \multicolumn{1}{c|}{$\mathrm{N}$} & \multicolumn{1}{c|}{$\%$} & $\mathrm{~N}$ & $\%$ & $\mathrm{~N}$ & $\%$ & $\mathrm{~N}$ & $\%$ \\
\hline Viseu-Universidade & & & & & & & & & & \\
Católica & 3 & 13,04 & 40 & 28,78 & 74 & 37,76 & 51 & 37,50 & 168 & 34,01 \\
Outra cidade-Univ. & & & & & & & & & & \\
Estatal & 19 & 82,61 & 99 & 71,22 & 120 & 61,22 & 82 & 60,29 & 320 & 64,78 \\
Não resposta & 1 & 4,35 & 0 & 0,00 & 2 & 1,02 & 3 & 2,21 & 6 & 1,21 \\
\hline
\end{tabular}

Optavam por ficar em Viseu a estudar na UCV 13,04\% dos sujeitos da classe inferior baixa.

Preferiam ir estudar para outra cidade, na Universidade Estatal, 82,61\% de sujeitos da classe superior, $71,22 \%$ da classe média, $61,22 \%$ da classe inferior alta e $60,29 \%$ da classe inferior baixa.

É baixa a percentagem de não respostas para todas as classes.

Quanto à justificação da escolha ${ }^{34}$, verificamos que as razões apontadas pelos sujeitos da classe superior foram o facto de assim thes ser permitido estabelecer novas relações $(39,13 \%)$ e por ser a universidade que garante melhores condições para tirar um curso $(21,74 \%)$. Verificamos $26,06 \%$ de não respostas.

Pelos sujeitos da classe superior média as razões mais apresentadas foram a possibilidade de estabelecer novas relações $(25,90 \%)$ e por ser a universidade que garante melhores condições para tirar um curso $(18,71 \%)$. Verificamos $5,04 \%$ de não respostas.

Os sujeitos da classe inferior alta justificaram a escolha por razões económicas $(27,04 \%)$, por poderem ficar mais próximos de casa $(22,45 \%)$ e por lhes permitir estabelecer novas relações $(19,39 \%)$. Verificamos $10,20 \%$ de não respostas.

Relativamente à classe inferior baixa, 38,97\% justificam a sua escolha por razões económicas, $26,47 \%$ por poderem ficar mais próximos de casa e $13,97 \%$ por ser a universidade que garante melhores condições para tirar um curso. Verificamos $11,03 \%$ de não respostas. 
QUADRO XXXIII

Centro da UCP por que optavam os sujeitos das diferentes classes sociais

\begin{tabular}{|c|c|c|c|c|c|c|c|c|c|c|}
\hline & \multicolumn{2}{|c|}{ C. SUP. } & \multicolumn{2}{|c|}{ C: MED. } & \multicolumn{2}{|c|}{ C. I. A. } & \multicolumn{2}{|c|}{ C.I. B. } & \multicolumn{2}{|c|}{ TOTAL } \\
\hline & $\mathrm{N}$ & $\%$ & $\mathbf{N}$ & $\%$ & $\mathbf{N}$ & $\%$ & $\mathbf{N}$ & $\%$ & $\mathrm{~N}$ & $\%$ \\
\hline Viseu & 5 & 21,74 & 62 & 44,60 & 116 & 59,18 & 87 & 63,97 & 270 & 54,66 \\
\hline Braga & 1 & 4,35 & 1 & 0,72 & 5 & 2,55 & 5 & 3,68 & 12 & 2,43 \\
\hline Lisboa & 6 & 26,09 & 36 & 25,90 & 36 & 18,37 & 25 & 18,38 & 103 & 20,85 \\
\hline Porto & 11 & 47,83 & 39 & 28,06 & 36 & 18,37 & 15 & 11,03 & 101 & 20,45 \\
\hline Não resposta & 0 & 0,00 & 1 & 0,72 & 3 & 1,53 & 4 & 2,94 & 8 & 1,62 \\
\hline
\end{tabular}

O Centro da Universidade Católica mais escolhido pelos sujeitos da classe superior foi o do Porto $(47,83 \%)$, seguido pelo de Lisboa $(26,09 \%)$ e de Viseu $(21,74 \%)$; o Centro escolhido em último lugar foi o de Braga $(4,35 \%)$.

Os sujeitos da classe média escolhem em primeiro lugar a UCP-Viseu $(44,60 \%)$, seguida da UCP-Porto $(28,06 \%)$ e UCP-Lisboa $(25,90 \%)$; em último lugar escolhem a UCP-Braga $(0,72 \%)$.

O Centro da Universidade Católica mais escolhido pelos sujeitos da classe inferior alta foi Viseu (59,18\%), seguido do Porto e Lisboa (18,37\%) e de Braga com apenas $2,55 \%$.

Pelos sujeitos da classe inferior baixa, o Centro mais escolhido foi o de Viseu $(63,97 \%)$, seguido de Lisboa $(18,38 \%)$ e Porto $(11,03 \%)$; por último escolheram o de Braga (3,68\%). Foi baixa a percentagem de não respostas.

Quanto à justificação da escolha ${ }^{35}$, verificamos que as principais razões apontadas pelos sujeitos da classe superior para a escolha do Centro da Universidade Católica foram o facto de ficarem mais perto de casa $(47,83 \%)$, por pretenderem estabelecer novas relações e por estarem na cidade que oferece as melhores condições.

As razões apresentadas pelos sujeitos da classe média foram, sobretudo, o facto de ficar mais perto de casa $(58,27 \%)$, por estar na cidade que oferece melhores condições $(15,83 \%)$ e por ser o Centro que garante as melhores condições para tirar um curso $(14,39 \%)$.

As classes inferior alta e inferior baixa apresentam como principais justificações, para a escolha do Centro, o facto de ficar mais perto de casa, por razões económicas e por estar na cidade que oferece as melhores condições.

A percentagem de não respostas mais elevada foi apresentada pela classe inferior baixa $(8,09 \%)$. 


\section{CONCLUSÕES}

O estudo foi realizado com a intenção de analisar as preferências dos jovens para a entrada no ensino superior.

A análise das respostas às perguntas por classes, embora não tendo havido oportunidade de apresentar todos os dados, permitiu atingir todos os objectivos propostos.

É baixa a percentagem de sujeitos dos $9 .^{\circ}, 11 .^{\circ}$ e $12 .^{\circ}$ anos que não pretendem ingressar no ensino superior.

Os sujeitos do $9 .^{\circ}$ ano que pretendem continuar a estudar fazem-no por vontade própria e atribuem enorme importância aos estudos com vista à vida futura, e também como condição para o seu ingresso no ensino superior.

Assim, ao escolherem a área de estudos a partir do $90^{\circ}$ ano, os jovens já estão a pensar no seu futuro profissional e, consequentemente, no curso que para $o$ efeito têm de frequentar no ensino superior.

No entanto, nem sempre conseguem conciliar os desejos profissionais com o curso escolhido.

São poucos os sujeitos do $9 .^{\circ}$ ano que têm ideia da universidade que gostariam de frequentar; desses, a maior percentagem escolhe a Universidade de Coimbra. Apresentam como principais razões para esta escolha o facto de se tratar de uma universidade que oferece boas condições e que se encontra próxima do mercado de trabalho.

A cidade, onde a universidade está instalada, pode também influenciar a escolha, pela distância, pelo ambiente e pelas condições que oferece.

Em relação à Universidade Católica, os sujeitos optavam pelo Centro Regional de Viseu, sobretudo pelo facto de poderem ficar mais próximos de casa.

O 9. ano de escolaridade apresenta grande importância para o estudo em causa, pois os alunos deste ano serão os possíveis beneficiários do desenvolvimento do CRV-UCP.

As suas opiniões poderão contribuir para as decisões a tomar no âmbito da criação de novos cursos e também no campo da sua divulgação.

As profissões mais escolhidas pelos sujeitos dos $11 . \% 12 .^{\circ}$ anos de escolaridade, que pretendem ingressar no ensino superior, estão relacionadas com Direito, Medicina, Professores do Ensino Secundário e Gestão, o que em certa medida vai influenciar a escolha do curso superior e da universidade que pretendem frequentar.

Nem todos os sujeitos que desejam frequentar um curso superior sabem em que universidade gostariam de o tirar, mas no entanto a mais escolhida foi a Universidade de Coimbra. Esta é considerada pelos jovens como uma Universidade de prestígio, que dá boa formação e está instalada numa cidade que reúne as condições ideais para tirar um curso superior.

Viseu é escolhida sobretudo pelos jovens pertencentes às classes inferior alta $\mathrm{e}$ inferior baixa. 
Em termos de universidade, em primeiro lugar escolhem a Universidade Estatal e em segundo a Universidade Católica.

A escolha está relacionada sobretudo com o reconhecimento da universidade para a formação de licenciados e com razões de ordem económica.

Os jovens valorizam ainda a possibilidade de estabelecer novos contactos, fazer novas amizades e conhecer novos ambientes.

Pensando apenas em termos de diferentes Centros da Universidade Católica Portuguesa, o mais escolhido é o de Viseu, sobretudo porque permitia aos jovens continuarem a viver perto de casa, da família e dos amigos.

\section{NOTAS}

1. O trabalho de investigação foi realizado por Armando Lacerda e Graça Ferreira no ano lectivo de 1990/1991. Encontra-se, para consulta, na Biblioteca do CRV-UCP e, doravante, será abreviadamente citado pelas iniciais PJIES.

2. Estes dados foram fornecidos pelos Conselhos Directivos de cada escola em Dezembro de 1990. Tivemos a preocupação de eliminar os alunos de cada escola que já tinham anulado a sua matrícula ou pedido a transferência para outra e registar os que surgiram posteriormente à data da matrícula.

3. Estes $16.00 \%$ foram acrescentados com a intenção de superar casos de transferências para a escola em causa ou outras eventualidades não encontradas na altura do reconhecimento do universo.

4. $\mathrm{N} / \mathrm{n}=10$ para os alunos do $9 .^{\circ}$ ano; $\mathrm{N} / \mathrm{n}=9$ para os alunos do $11 .^{\circ}$ ano; $\mathrm{N} / \mathrm{n}=8$ para os alunos do $12 .^{\circ}$ ano.

5. Para a análise de conteúdo seguimos as técnicas indicadas por Bardin (1977).

6. Foi necessário substituir 29 alunos do $9 .^{\circ}$ ano, 94 do $11 .^{\circ}$ ano e 109 do $12 .^{\circ}$ ano.

7. Utilizando as técnicas indicadas por Bardin (1977).

8. As quatro classes sociais apresentadas pelos autores foram distinguidas com base nos dados do X Recenseamento da População (1960). Vide PJIES, ANEXO X, a distribuição das categorias profissionais por classe social apresentada por Nunes e Miranda (1969).

9. Considerámos que uma percentagem de sujeitos sentiria dificuldade em admitir pertencer à classe inferior baixa e por isso apresentámos a denominação classe inferior baixa (classe popular).

10. Vide PJIES, QUADRO XLV.

11. Vide PJIES, QUADRO LIX.

12. Vide PJIES, QUADRO LXI.

13. Vide PIIES, ANEXO XI.

14. Vide PJIES, ANEXO XII.

15. Vide PJIES, QUADRO LXIII.

16. Vide PJIES, ANEXO XV.

17. Vide PJIES, ANEXO XVI. 
18. Vide PJIES, QUADRO LXVIII.

19. Vide PJIES, QUADRO LXX.

20. Vide PJIES, QUADRO LXXIV.

21. Vide PJIES, QUADRO LXXXII.

22. Vide PJIES, QUADRO LXXXVI.

23. Vide PJIES, QUADRO CXII.

24. Vide PJIES, QUADRO CXIV.

25. Vide PJIES, QUADRO CXVI.

26. Vide PJIES, ANEXO XVIII.

27. Vide PJIES, ANEXO XIX.

28. Vide PJIES, QUADRO CXVIII.

29. Vide PJIES, ANEXO XXII.

30. Vide PJIES, ANEXO XXIII.

31. Vide PJIES, QUADRO CXXIII.

32. Vide PJIES, QUADRO CXXV.

33. Vide PJIES, QUADRO CXXIX.

34. Vide PJIES, QUADRO CXXXVII.

35. Vide PJIES, QUADRO CXII.

\section{BIBLIOGRAFIA}

\section{Livros}

ALALUF, M. \& BAL, M. B. de, 1986, Les temps du labeurs, Bruxelles, Université de Bruxelles.

BARDIN, L., 1977, Análise de conteúdo, Lisboa, Edições 70.

BRITO, J., 1982, Notas sobre os recursos energéticos, Lisboa.

CHERKAOUI, M., 1986, Sociologia da Educação, Mem Martins, Europa-América.

CHIAVENATO, I., 1986, Administração de recursos humanos, 2." ed., São Paulo, Atlas, vols. 2 e 3.

DONELA, MEADOWS, D., H. V., 1972, Os limites do crescimento, Lisboa, Publ. Dom Quixote.

Documentos Conciliares e Pontifícios, 1983, Concílio Ecuménico Vaticano II, Lisboa, Editorial A. O..

FIGUEIREDO, E., 1988, Portugal nos próximos 20 anos - Conflito de gerações - Conflito de valores, Lisboa, Fundação Calouste Gulbenkian, vol 2.

FRIEDMANN, G. \& NAVILLE, P., 1973, Tratado de Sociologia do Trabalho, São Paulo, Cultrix, vols 1 e 2 .

HANNOUM, H., 1975, Os conflitos da educação, Lisboa, Sociocultura. 
I.E.D., 1983, Situação, Problemas e perspectivas da juventude em Portugal, Lisboa, Fundação Calouste Gulbenkian.

KIESS, H. O. \& BLOOMQUIST, D. W., 1985, Psichological research methods - A conceptual approach, E.U.A., Human Sciences Press.

LEYENS, J., 1985, Teorias da personalidade na dinâmica social, Lisboa, Verbo.

LOPES, E. \& GRILO, M., H. V., 1989, Portugal, desafio dos anos 90, Lisboa, Editorial Presença.

MEHOK, W. Y., 1963, An introduction to replicated subsampling.

MUSGRAVE, P., 1979, Sociologia da Educação, Lisboa, Fundação Calouste Gulbenkian.

NUTTIN, MONTAGERO, H. V., 1977, Du temps biologique au temps psychologique, Paris, PUF.

PINTO, V., 1989, Revelação e Fé, Braga, Apostolado da Oração, vol. 1.

RAPOSO, N., 1981, O computador e a avaliação da aprendizagem, Coimbra, Coimbra Editora.

ROUSSELET, J., 1974, A alergia ao trabalho, Lisboa, Edições 70.

TOFFLER, A., 1984, A Terceira Vaga, Lisboa, Livros do Brasil.

TROMMSDORFF, G., 1983, Future time orientation and its relevance for development as action, Westphalia, University of Rhine.

\section{Legislação e publicações perídicas}

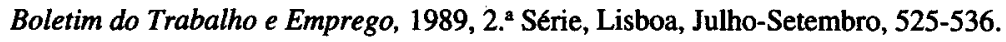

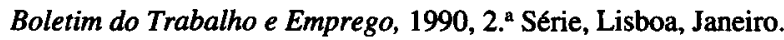

- Boletim do Trabalho e Emprego, 1991. Projecto de diploma para a apreciação pública, Separata 2, Lisboa, Abril, 3-14.

Lei de Bases do Sistema Educativo n. ${ }^{\circ} 46 / 86$, Outubro.

BORN, M., 1984, "Les Structures de la Perspective Temporelle", Psychologica Belgica, XXIV-2, 105-116.

BOUFFARD, L., LAPIERRE, H. V., 1987, "La Perspective Future Dans le Comportement Humain", Revue Québécoise de Psychologie, vol. 8.

CONDE, I., 1990, "Identidade Nacional e Social dos Jovens", Análise Social, 3." série, vol. XXV (108/109), 675-693.

CRUZ, M., 1990, "A participação Política da Juventude em Portugal - As élites Políticas Juvenis", Análise Social, 3. série, vol. XXV (105/106), 223-249.

FONTES, C., 1990, "Planeamento da Formação", Formar, 1, 37-43.

M.E.S.S., 1988, “Terminologia da Formação Profissional: Alguns Conceitos de Base", S.I.C.T.M.E.S.S..

MESS/SEEFP, 1990, "Novos Rumos Para a Formação Profissional. Quadro de Apoio 19901993", IEFP.

NUNES, A. S. \& MIRANDA, J. O. , 1969, “A Composição Social da População Portuguesa. Aspectos e implicações”, Análise Social, 7, 27/28, 333-381. 
PAIS, J., 1990, "Lazeres e Sociabilidades Juvenis-Um ensaio de Análises Etnográfica", Análise Social, 3. ${ }^{\mathrm{a}}$ série, vol. XXV (108/109), 591-644.

PERROT, M., 1979, "Os Problemas de Mão-de-obra Industrial", Sociologia do Trabalho - Organização do Trabalho Industrial, 14- 55.

REAL, I., 1990, “O Planeamento da Formação para o Desenvolvimento Regional Integrado", Formar, 1, 44-47.

SCHMIDT, L., 1990, "Jovens: Família, Dinheiro, Autonomia", Análise Social, 3." série, vol. XXV (108/109), 645-674.

SILVA, L., 1990, "O Direito de bater na Mulher-Violência Interconjugal na Sociedade Portuguesa", Análise Social, 4. " série, vol XXVI (111), 385-396. 